\title{
Evaluating convection-permitting ensemble forecasts of precipitation over Southeast Asia
}

Article

Accepted Version

Ferrett, S. ORCID: https://orcid.org/0000-0003-4726-847X, Frame, T. H. A., Methven, J., Holloway, C. E. ORCID: https://orcid.org/0000-0001-9903-8989, Webster, S., Stein, T. H.M. ORCID: https://orcid.org/0000-0002-9215-5397 and Cafaro, C. ORCID: https://orcid.org/0000-0001-8063-4887 (2021) Evaluating convection-permitting ensemble forecasts of precipitation over Southeast Asia. Weather and Forecasting, 36 (4). pp. 1199-1217. ISSN 0882-8156 doi: https://doi.org/10.1175/WAF-D-20-0216.1 Available at https://centaur.reading.ac.uk/96819/

It is advisable to refer to the publisher's version if you intend to cite from the work. See Guidance on citing.

To link to this article DOI: http://dx.doi.org/10.1175/WAF-D-20-0216.1

Publisher: American Meteorological Society

All outputs in CentAUR are protected by Intellectual Property Rights law, including copyright law. Copyright and IPR is retained by the creators or other copyright holders. Terms and conditions for use of this material are defined in the End User Agreement. 


\section{www.reading.ac.uk/centaur}

\section{CentAUR}

Central Archive at the University of Reading

Reading's research outputs online 
3 Samantha Ferrett ${ }^{1}$, Thomas H. A. Frame ${ }^{1}$, John Methven ${ }^{1}$, Christopher E. Holloway ${ }^{1}$,

4 Stuart Webster ${ }^{2}$, Thorwald H.M. Stein ${ }^{1}$, Carlo Cafaro ${ }^{1}$

5

$6 \quad{ }^{1}$ Department of Meteorology, University of Reading, Reading, UK

$7 \quad{ }^{2}$ Met Office, Exeter, UK

8

9

10 Corresponding Author:

11 Samantha Ferrett

12 s.j.ferrett@ reading.ac.uk

13 Department of Meteorology

14 Meteorology Building

15 Whiteknights Road

16 Earley Gate

17 Reading, RG6 6ET 
19 Forecasting rainfall in the tropics is a major challenge for numerical weather

20 prediction. Convection-permitting (CP) models are intended to enable forecasts of

21 high-impact weather events. Development and operation of these models in the

22 tropics has only just been realised. This study describes and evaluates a suite of

23 recently developed Met Office Unified Model CP ensemble forecasts over three

24 domains in Southeast Asia, covering Malaysia, Indonesia and the Philippines.

25 Fractions Skill Score is used to assess the spatial scale-dependence of skill in

26 forecasts of precipitation during October 2018 - March 2019. CP forecasts are skilful

27 for 3-hour precipitation accumulations at spatial scales greater than $200 \mathrm{~km}$ in all

28 domains during the first day of forecasts. Skill decreases with lead time but varies

29 depending on time of day over Malaysia and Indonesia, due to the importance of the

30 diurnal cycle in driving rainfall in those regions. Skill is largest during daytime when

31 precipitation is over land and is constrained by orography. Comparison of CP

32 ensembles using 2.2, 4.5 and $8.8 \mathrm{~km}$ grid spacing and an $8.8 \mathrm{~km}$ ensemble with

33 parameterised convection reveals that varying resolution has much less effect on

34 ensemble skill and spread than the representation of convection. The parameterised

35 ensemble is less skilful than CP ensembles over Malaysia and Indonesia and more

36 skilful over the Philippines; however, the parameterised ensemble has large drops in

37 skill and spread related to deficiencies in its diurnal cycle representation. All

38 ensembles are under-spread indicating that future model development should focus on

39 this issue. 
41 The nations of South East Asia are susceptible to devastating impacts of heavy rainfall such as flooding and landslides. Deep convection is central to extreme rainfall intensity in the region (e.g. Matsumoto et al., 2017) and it also plays an active part in the dynamics of the larger scale atmospheric phenomena that dominate in the region. There are many contributing factors to the occurrence of convective rainfall events on a range of spatial and temporal scales from the longest to the shortest such as: the El Nino-Southern Oscillation (Hamada et al. 2012; Villafuerte and Matsumoto 2015; Supari et al. 2018), the Madden-Julian Oscillation (MJO; Wu et al. 2013; Peatman et al. 2014; Xavier et al. 2014; Birch et al. 2016; Vincent and Lane 2018; Lestari et al. 2019), cold surges (Chang et al. 2005; Lim et al. 2017), equatorial waves (Ferrett et al. 2020) and tropical cyclones (Takahashi and Yasunari 2008).

Rainfall variability in many regions of Southeast Asia has a strong diurnal cycle, a result of local land-sea breeze circulations, surface heating during the day and the delayed response of deep convection (e.g. Mori et al., 2004; Yamanaka, 2016). Coarse-grid models (including all current operational global models) rely on convection parameterisations and are known to struggle to capture accurately tropical rainfall features (e.g. Neale \& Slingo, 2003; Johnson et al., 2016), such as the diurnal cycle (Yang and Slingo 2001; Love et al. 2011), the propagation of the MJO and equatorial waves (Lin et al. 2006; Holloway et al. 2013; Peatman et al. 2015; Peatman et al. 2018), and other aspects of convection (Qian 2008; Pearson et al. 2010, 2014).

61 Consequently, there has been considerable effort to improve the representation of 62 these processes in models, namely by increasing model resolution so that deep convection can be explicitly simulated by the dynamical core of the model reducing 
the need for convection parameterisations. In a numerical weather prediction context, there is a trade-off between resolution, model domain size and ensemble size.

Resolving deep convection requires a model capable of representing non-hydrostatic, compressible dynamics and a horizontal (and vertical) grid spacing that is much less than the depth of deep convective updrafts $(10-20 \mathrm{~km})$. If achieving this resolution requires that the domain is too small, the behaviour of systems developing in the domain will be almost completely specified by the lateral boundary conditions imposed by the parent, lower resolution model, in which the model is nested and there is no benefit in the high-resolution prediction. If the domain is large enough to allow the interior solution of the high-resolution model to deviate from that of its parent, then a compromise must be made on resolution and ensemble size in order to obtain an ensemble forecast in near-real time.

The current state-of-the-art for operational numerical weather prediction is that deep convective motions are only partially resolved; such models have horizontal grid spacing of the order 1-10 km and are described as "convection-permitting" (CP) and the ensembles are small ( $\sim 10$ members). Often shallow moist convection is not resolved and may be parametrized as part of the convective regime of the boundary layer scheme, although the approach taken to turbulence and boundary layer parameterization also depends on model resolution. While CP forecasts are more computationally expensive, they are better able to represent processes that drive convection (Clark et al. 2016). Studies have shown significant improvement in the initiation of convection (Mittermaier et al. 2013; Birch et al., 2014a; 2014b; 2015; Woodhams et al., 2018), the diurnal cycle of convection (Sato et al. 2009; Love et al. 2011; Birch et al. 2015), and large-scale modes that drive convection (Miura et al. 
2007; Holloway et al. 2013) in CP models compared to those with parameterised convection.

Forecasting at convective scales is inherently uncertain, even at short lead times (Hohenegger and Schar 2007). This uncertainty can be associated with many things, such as model physics, initial conditions, or boundary conditions. Therefore, ensembles of forecasts are used to account for uncertainty. These convective-scale ensembles have been developed in regions world-wide (e.g. Gebhardt et al. 2011; Golding et al. 2014; Schwartz et al. 2015; Hagelin et al. 2017; Roberts et al. 2019) with obvious improvements in forecast accuracy compared to a single forecast (Hagelin et al. 2017). While there have been many studies of the benefits of using ensemble forecasts to predict the risk of high impact weather in the extra-tropics (Hanley et al. 2013; Bednarczyk and Ancell 2015) and CP ensembles have been shown to add value to forecasts of mesoscale phenomena such as sea breezes (Cafaro et al. 2019), there are fewer studies examining how CP ensembles may benefit forecasts of extreme rainfall in the tropics more widely and Southeast Asia specifically. A few recent studies have focused on CP ensemble forecasts over Singapore and the surrounding region (Porson et al. 2019; Sun et al. 2020). These studies focused on comparing the effect of global models in which CP ensembles are nested on forecast skill and spread (Porson et al. 2019) and comparing objective and subjective evaluation methods of forecasts of squall lines (Sun et al. 2020). Both studies evaluate against observations in relatively small regions around Singapore (approx. 400km x 400km).

In this study $\mathrm{CP}$ ensemble forecasts are one-way nested in limited area domains within the operational MOGREPS global ensemble using three horizontal resolutions. 
112 Three domains within the Southeast Asia region are examined, including Peninsular

113 Malaysia, Java and the Philippines. The aim of this study is to quantify the usefulness

114 of CP ensemble forecasts of precipitation in this region, the scale dependence of

115 forecast skill as well as the role of the diurnal cycle in forecast skill.

116 Descriptions of the $\mathrm{CP}$ ensembles and other datasets used for the analysis are

117 provided in Section 2. The methods for evaluation of forecasts using observations are

118 outlined in Section 3. Section 3 also provides details of the construction of a variation

119 of the ensemble forecast, and a persistence forecast, that are used to assess the role of

120 the diurnal cycle in forecast skill. Section 4 provides the results of the study, detailing

121 the spatial scale-dependence in the skill of the forecasts, the role of the diurnal cycle

122 and the spread of the ensembles in relation to mean forecast error as a function of lead 123 time. Results are summarised in Section 5.

$124 \underline{2 . D a t a}$

$125 \quad 2.1$ Ensemble forecasts

126 The convection-permitting (CP) ensemble forecasts consist of 18 ensemble members

127 and were created by nesting limited area simulations using the Met Office Unified

128 Model (MetUM) within the 18-member operational Global ensemble of the Met

129 Office Global and Regional Ensemble Prediction System (MOGREPS-G). The CP

130 ensembles were initialised twice daily (00 UTC and 12 UTC) over a period of six

131 months spanning October 2018-March 2019, producing hourly forecast output in

132 three domains corresponding to Malaysia, Indonesia and the Philippines (Figure 1)

133 out to 120 hours, except for $2.2 \mathrm{~km}$ forecasts which are ran for 60 hours. Only the 00

134 UTC forecasts are shown here, however analysis has also been carried out for the 12 
135 UTC forecasts with similar results after the initial model spin-up period, albeit

136 displaced by twelve hours.

137 The forecasts use horizontal grid spacing of 2.2, 4.5 and $8.8 \mathrm{~km}$ and are nested in

138 MOGREPS-G that has a horizontal grid spacing of $20 \mathrm{~km}$ at the equator and 70

139 vertical levels. The global ensemble initial conditions are derived from the ensemble

140 transform Kalman filter (ETKF) method and a stochastic parameterisation scheme is

141 also used in the global ensemble (Bowler et al., 2008). Each member of the limited

142 area ensembles is obtained by one-way nesting from a MOGREPS-G forecast

143 (dynamical downscaling). No additional stochastic perturbation scheme is used within

144 the CP forecasts. The MetUM dynamical core solves a non-hydrostatic, deep

145 atmosphere equation set using a semi-implicit, semi-Lagrangian time-stepping

146 method and has 80 vertical levels. The science configuration of the dynamics and

147 physics schemes of the atmosphere and land used for the CP simulations in tropical

148 regions, "RAL1-T", is documented in Bush et al. (2020). RAL1-T is the tropical

149 subversion of RAL1 (Regional Atmosphere and Land configuration). The tropical

150 version is required since the mid-latitude version (RAL1-M) has relatively weak

151 turbulent mixing and stochastic perturbations which causes convection to initiate too

152 early and convective cells to be small in the tropics. In order to account for this,

153 RAL1-T uses the prognostic cloud prognostic condensate (PC2) cloud scheme

154 (Wilson et al. 2008), has an interactive boundary layer free-atmosphere mixing length

155 and has no stochastic boundary layer perturbations.

156 An $8.8 \mathrm{~km}$ ensemble with parameterised convection is also included and uses the

157 configuration of the operational global atmosphere version 6 (GA6) documented in

158 Walters et al. (2017). This ensemble is referred to throughout as the GA ensemble. 
159 Before analysis is carried out all forecasts are re-gridded to a common $9 \mathrm{~km}$ grid

160 using an area-weighted conservative re-gridding scheme included in the python

161 library "Iris" developed by the Met Office.

\subsection{GPM-IMERG}

163 To verify forecasts, rainfall is taken from The Integrated Multi-satellitE Retrievals for

164 GPM (GPM-IMERG; Huffman et al. 2019). The product used is Level 3 half-hourly

165 Final Run Precipitation at a resolution of $0.1^{\circ}$ and combines precipitation estimates

166 from GPM constellation satellites (see

167 https://gpm.nasa.gov/missions/GPM/constellation) and Global Precipitation

168 Climatology Centre (GPCC) precipitation rain-gauges. Precipitation estimates from

169 passive microwave radiometers are combined with estimates from infrared data from

170 geostationary weather satellites. Analyses of monthly GPCC gauge accumulations are

171 then used to reduce biases in the multi-satellite monthly averages where available.

172 Results using this dataset are referred to in this paper as "GPM" for simplicity.

173 Before any analysis takes place, the GPM precipitation field is also converted to an

174 average hourly rain rate and is interpolated from a 0.1 degree grid to a common $9 \mathrm{~km}$

175 grid. Note that this is a slightly higher resolution than the native grid but the area-

176 weighted conservative interpolation scheme maps between staggered grids with

177 similar spacings without affecting integrals over larger scales.. It should also be noted

178 that generally both heavy rainfall and rainfall over ocean tend to be underestimated by

179 GPM (Tan and Duan 2017; Kahn and Maggioni 2019; Sunilkumar 2019; Tan and

180 Santo 2019). Nonetheless, studies suggest that in the Philippines, unless examining

181 very heavy rainfall $\left(99^{\text {th }}\right.$ percentile), GPM captures rainfall relatively well

182 (Sunilkumar 2019). The Singapore diurnal cycle of rainfall is well represented in 
183 GPM (Tan et al. 2019) and Tan and Santo (2018) also concluded that GPM was a

184 reliable precipitation source for a flooding event in Malaysia during 2014-2015. A

185 recent study finds that GPM precipitation is similar to local precipitation for

186 percentiles between the $85^{\text {th }}$ and $95^{\text {th }}$ and concludes that IMERG can be used for

187 forecast evaluation of precipitation up to the 95th percentile (De Silva et al. 2021).

188

189

190

191

192

193

194

195

196

197

198

199

200

201

202

203

\section{Methods}

\subsection{Fractions Skill Score}

The Fractions Skill Score (FSS; Roberts \& Lean, 2008) is a metric that compares two gridded fields and measures the degree of correspondence as a function of spatial scale. In order to calculate the FSS the re-gridded (see section 2) forecast and observation fields are converted into binary fields ( 1 or 0$)$ based on values in each grid cell being above or below a threshold. In this study a threshold of the $95^{\text {th }}$ percentile of rainfall is used, calculated using all grid cells (including zero values) over the re-gridded domains and the six months spanned by the forecasts. The threshold is calculated separately using GPM-IMERG and the ensemble forecast data for the GPM and forecast binary fields respectively. The threshold varies depending on time of day in the case of GPM and depending on lead time in the case of forecasts. Percentiles are used for the threshold choice in calculations (rather than a fixed rain rate threshold) to counteract the influence of intensity bias that effects the frequency of "event" occurrence.

A neighbourhood length ( $\mathrm{N}$; number of grid cells) is defined and is used to convert regularly gridded fields into fractions based on how many grid cells within neighbourhoods of size $\mathrm{NxN}$ have cell values exceeding the threshold (see figure 2 in Roberts \& Lean, 2008). The FSS is given as: 


$$
F S S_{(N)}=1-\frac{M S E_{(N)}}{M S E_{(N) r e f}}
$$

208 where

$$
\begin{gathered}
M S E_{(N)}=\frac{1}{N_{x} N_{y}} \sum_{i=1}^{N_{x}} \sum_{j=1}^{N_{y}}\left[O_{(N) i, j}-M_{(N) i, j}\right]^{2} \\
M S E_{(N) \mathrm{ref}}=\frac{1}{N_{x} N_{y}}\left[\sum_{i=1}^{N_{x}} \sum_{j=1}^{N_{y}} O_{(N) i, j}^{2}+\sum_{i=1}^{N_{x}} \sum_{j=1}^{N_{y}} M_{(N) i, j}^{2}\right]
\end{gathered}
$$

211 Such that $O_{(N)}$ and $M_{(N)}$ are the fields of fractions for neighbourhood length $\mathrm{N}$ for

212 observations and models respectively. $\mathrm{N}_{\mathrm{x}}$ and $\mathrm{N}_{\mathrm{y}}$ are the number of neighbourhoods in

213 the full domain along the longitude and latitude axes respectively.

214 This calculation can be computed for varying $\mathrm{N}$ to obtain FSS as a function of 215 neighbourhood size. The aim is to allow for the fact that the location of features on 216 the smallest scales in CP models, associated with convective updrafts, is highly 217 unpredictable, while the probability that a certain fraction of neighbourhood area is 218 occupied by precipitation cells (reaching an intensity threshold) may be predicted 219 skilfully. Furthermore, in the absence of data assimilation for high resolution 220 observations (such as radar) there is no information in the initial conditions on the 221 smaller scales. The FSS value must lie between 1 and 0 with an FSS of 1 indicating a 222 perfect forecast. FSS is expected to increase with neighbourhood size. A threshold of 223 FSS can be used to determine the minimum spatial scale at which the forecast is 224 considered skilful. This is taken to be 0.5 if observed rainfall frequency is sufficiently 225 low (see Roberts \& Lean, 2008).

226 Using this calculation as a basis, this study examines the ensemble-aggregated FSS 227 (eFSS), the dispersion FSS (dFSS) and the localised FSS (LFSS). Because this study 228 deals with an ensemble, it is required that FSS for all ensemble members is 
summarised, so to do this the average of $\mathrm{MSE}_{(\mathrm{N})}$ and $\mathrm{MSE}_{(\mathrm{N}) \text { ref }}$ is taken over all ensemble members and all forecasts in the six-month period prior to calculation of the

231 FSS using Equ. 1, resulting in the eFSS (Dey et al. 2014).

232 In order to obtain a measure of ensemble spread in relation to skill the dFSS is also

233 calculated. The method for this is very similar to that of the eFSS except rather than

234 compare ensemble members to observations they are compared to the control member

235 of the ensemble (Rezacova et al. 2009; Dey et al. 2014). This provides a metric that

236 demonstrates how similar precipitation patterns are between members of the

237 ensemble. It is possible that model bias can influence metrics of spread (e.g. Wang et.

238 al 2018). However, this FSS-based metric uses a percentile threshold, therefore

239 accounting for precipitation intensity biases as part of the calculation.

240 Finally, a localised FSS (Woodhams et al. 2018) is used to determine regions in the

241 domain that have particularly high or low values of skill relative to the full domain.

242 For this metric the $\mathrm{MSE}_{(\mathrm{N})}$ and $\mathrm{MSE}_{(\mathrm{N}) \text { ref }}$ are calculated for each neighbourhood (using

243 the same domain-wide threshold precipitation rate, calculated from a percentile of the

244 data from all forecasts at all grid points, as described above) but are not averaged over 245 the domain prior to FSS calculation.

\section{3.2. Persistence Forecast and 'Shifted Forecast'}

247 Forecast skill should be benchmarked against some more simple climatological or 248 persistence-based reference forecast, since a useful forecast has to provide greater 249 skill than these basic methods. The FSS is calculated for three variations of forecast 250 over Oct 2018-Mar 2019. The three variations are:

- The standard CP ensemble forecasts. 
- A 'shifted ensemble forecast', where forecast time stamps (for all lead times) are shifted by adding one day such that the forecast is verified against observations that occur a day later than the actual forecast verification times.

- A persistence forecast based on forward extrapolation from observations.

The 'shifted forecast' tests how much potential predictability comes from the similarity of the observed diurnal cycle from one day to the next (e.g., the pattern of precipitation over mountains and coasts). If the standard ensemble were no more skilful than the shifted forecast, it would imply that the model gives little useful information beyond its representation of the diurnal cycle in that flow regime and season.

The persistence forecast uses no model data but instead uses hourly GPM precipitation from the day prior to forecast initialisation and replicates this for every 24-hour period of the forecast. If the observed precipitation at each location were dominated by its diurnal cycle then the persistence forecast would be almost perfect, while the 'shifted forecast' would have the same skill as the standard ensemble and comparison of both these forecasts with observations would reflect model bias.

However, longer timescale variability reduces the skill in the persistence forecast.

\section{Results}

\subsection{Rainfall climatology and $4.5 \mathrm{~km}$ forecast bias}

GPM $95^{\text {th }}$ percentile rainfall amounts in the Malaysia and Indonesia domains have a pronounced diurnal variation (dashed lines in Fig. 2b). Each domain has 2 peaks in rainfall; one around 0800 UTC and one around 2000 UTC. Malaysia and Philippines local time is UTC +8 hours and Indonesia local time is UTC +7 hours so these times 
correspond to local early evening when rainfall is mostly over land and local early morning when rainfall is mostly over ocean (Mori et al. 2004). The morning peak is

277 larger in the Malaysia domain than in the Indonesia domain. This is because rainfall

278 off the northwest coast of Sumatra is relatively strong during early morning. The

279 Philippines also has a variation throughout the day at similar times, but it is not as 280 pronounced as that in the other two domains (Fig. 2b). Only the $95^{\text {th }}$ percentile is 281 shown here, but the diurnal variation is consistent across other intensities, such as 282 average rainfall (not shown).

283 Percentiles are also calculated for forecasts. Note here that there is no averaging

284 involved in this calculation; the percentiles are calculated over all ensemble members, 285 all available forecasts and all grid points in the domain. For three-hourly 286 accumulations, the forecasts tend to underestimate the $95^{\text {th }}$ percentile rainfall in 287 comparison to GPM (Fig. 2b; Table 1). A similar result was found by Woodhams et 288 al. (2018) examining the $95^{\text {th }}$ percentile rainfall in East Africa forecasts. In contrast, 289 the $95^{\text {th }}$ percentile and mean of 24-hourly accumulations (Fig 2a; c) are overestimated, 290 as is the 3-hourly $99^{\text {th }}$ percentile (Table 1 ). Woodhams et al. (2018) find that in 291 Africa, at higher percentiles, such as 99\%, the CP model has higher values than observed. This is consistent with other studies that find that CP models in the extratropics overestimate rainfall amounts and persistence at very high intensities, but 294 underestimate rainfall at lower intensities (e.g. Kendon et al., 2012). However, bias 295 varies with lead time and CP models tend to have large amounts of rainfall after spin296 up. Note also that GPM is known to underestimate heavy rainfall events (Tan and 297 Duan 2017; Sunilkumar 2019) which will impact the extent to which the model shows 298 'bias' in comparison, though De Silva et. al (2021) find that $95^{\text {th }}$ percentile rainfall 299 over the Maritime Continent in GPM is suitable for forecast verification. 
Forecast precipitation rapidly increases during the initial hours of the forecast as the

301 model spins up, then declines with lead time (Fig. 2b). Variations with the diurnal

302 cycle are captured in the forecasts and peaks tend to occur at the correct times of day,

303 however the difference between the morning and evening peaks in rainfall is larger

304 than in GPM for the Malaysia and Indonesia domains. This suggests that rainfall over

305 the ocean is not as well captured in the model, or is overestimated in GPM, or a

306 combination of both. Since both heavy rainfall and rainfall over ocean tend to be

307 underestimated by GPM (Tan and Duan 2017; Kahn and Maggioni 2019; Sunilkumar

308 2019) this suggests the bias largely lies with the ensemble.

309 The $95^{\text {th }}$ percentile of precipitation in Malaysia forecasts also shows a relatively large

310 decrease following the first day of forecasts (Fig. 2). Such abrupt declines between

311 day 1 and day 3 are less evident in the Indonesia and Philippines domains (Fig. 2).

312 This visible drop in forecast precipitation for Malaysia may be a result of the spatial

313 distribution of precipitation in the Malaysia domain between ocean and land. Indeed,

314 when performing the percentile analysis for only land points and only ocean points

315 this decline is visible for the ocean rainfall but less so for the land rainfall (not

316 shown). This may be a result of differing drivers of rainfall in the regions. In the

317 Malaysia domain there is strong rainfall off the east coast of Sumatra, mainly driven

318 by convergence because of Sumatran orography (Wu et al. 2009). Rainfall in the

319 Indonesia domain is also largely driven by convergence lines between land masses,

320 though Wu et al. (2009) suggest that differences in orography of nearby land masses

321 may explain differences in ocean rainfall across Southeast Asia, such as between the

322 east coast of Sumatra and the west coast of Borneo. Therefore, the representation of

323 orography may be a large factor in diurnal cycle rainfall biases. 
324 Other aspects of the ensemble may also contribute to biases, such as initial conditions, 325 or the dynamical configuration and parameterizations of the parent ensemble. The 326 drop in rainfall is also found by Dipankar et al. (2020) in similar CP forecasts 327 covering Singapore and surrounding regions, such as Peninsular Malaysia and 328 Sumatra (SINGV). Dipankar et al. (2020) find that rainfall in a version of the model 329 driven by the global UM declines over ocean following 24 hours. This was not the 330 case in a version of the model driven by the ECMWF operational deterministic 331 forecast. It is suggested that this is primarily a result of the lateral boundary 332 conditions and a dry bias in global UM forecasts. Further analysis would be required 333 to determine the precise causes of bias here, and why they differ between regions.

334 Examining the spatial pattern of extreme precipitation in subsequent figures will 335 highlight the differences between the domains further. At longer lead times rainfall in 336 Malaysia and Indonesia domains continues to decrease, whereas Philippines rainfall 337 remains well captured at all lead times.

338 In GPM the highest values of $95^{\text {th }}$ percentile rainfall are over ocean, particularly over 339 the west coast of Sumatra (Fig. 3a;b). On the first day of forecasts the largest 340 precipitation amounts occur over mountainous regions of Sumatra and Java (Fig. $3413 \mathrm{~d} ; \mathrm{e})$, in contrast to GPM. There is some heavier rainfall off the west coast of Sumatra 342 where the observed rainfall peaks, but they are smaller than the land rainfall amounts.

343 The $95^{\text {th }}$ percentile of rainfall in the Philippines domain is well replicated with 344 comparable rainfall amounts to GPM in the south of the Philippines and the north-east 345 region of Borneo (Fig. 3f). Rainfall over mountains is heavier in the forecasts than 346 observed, explaining the discrepancies in the diurnal variations of rainfall (Fig. 2a; b). 
347 As lead time increases the $95^{\text {th }}$ percentile of rainfall off the west coast of Sumatra

348 decreases (Fig 3g). Rainfall over the ocean here decreases at a faster rate than that

349 over land between lead day 1 and lead day 3, explaining the large decrease in the

350 rainfall shown in Fig. 2 b after lead day 1 . The rainfall in the ocean to the north of Java

351 and in the Strait of Malacca does not show this decrease and even increases slightly.

352 As mentioned previously it seems likely there is a meteorological phenomenon in this

353 area that is more accurately captured than equivalent phenomena occurring west of

354 Sumatra and results in this differing behaviour. One possibility is convergence lines in 355 the Strait of Malacca resulting from land-sea breezes (Weller et al. 2017; Mohd Nor et 356 al. 2020) that are relatively well represented and persist in the forecast. At longer lead 357 times rainfall over mountainous regions continues to decrease (Fig. 3j;k). Rainfall 358 amounts over the Philippines show less change as lead time increases (Fig 31), as is 359 also indicated in Fig. 2.

\subsection{Skill of $4.5 \mathrm{~km}$ ensemble forecasts of daily precipitation accumulations}

361 The spatial scales over which forecasts of 24-hourly accumulated rainfall can be

362 considered skilful is assessed using the ensemble-aggregated Fractions Skill Score

363 (eFSS) to determine the smallest scale for useful forecast information from each of

364 the ensembles. Forecast skill of 24-hourly precipitation exceeds the skilful threshold

365 of 0.5 (red line in Fig. 4) at spatial scales greater than around $150 \mathrm{~km}$ on the first day

366 of forecasts for all three domains. Skill in the Philippines domain is slightly higher

367 and so forecasts are considered skilful at spatial scales greater than around $50 \mathrm{~km}$.

368 Skill decreases as lead time increases such that by the end of the 5-day forecasts only

369 spatial scales exceeding $350 \mathrm{~km}$ are considered skilful. It should be noted that here the

370 ensemble-average FSS is examined for comparison with ensemble spread, not a 
metric based on the probabilistic output of the FSS. The skill of the probabilistic ensemble output is slightly higher (not shown) and so the probabilistic forecasts will be able to be displayed usefully at slightly smaller scales than these (approximately 50-100km smaller depending on lead time and region).

While this is useful information for forecasting daily rainfall totals, variations in rainfall with the diurnal cycle and between land and sea mean that forecast skill is likely to vary with both location and time of day, particularly in Malaysia and Indonesia. To further understand contributors to forecast skill it is important to also examine diurnal variations in forecast skill, as well as spatial variations in skill.

\subsection{The role of the diurnal cycle in $4.5 \mathrm{~km}$ forecast skill}

As mentioned previously, rainfall has a strong diurnal cycle during the day and can be defined by two peaks: one during local early morning when rainfall is mostly over the ocean (not shown), and one during local early evening when rainfall is over land (Fig.

5). In GPM during early evening the highest values of rainfall are over Sumatra and Borneo (Fig. 5a; b). The rainfall over Sumatra tends to be located around orographic features: mountains run down the west side of Sumatra. There are also large amounts of rainfall just off the west coast of Sumatra. There are smaller amounts of rainfall over Peninsular Malaysia, Java and the southern Philippines (Fig 5a;b;c).

For forecasts, twelve hours after forecast initialisation the spatial pattern of $95^{\text {th }}$ percentile precipitation is similar to that in GPM but with varying amounts.

Precipitation in Sumatra is most strong in the northwest (Fig. 5d), unlike GPM where larger amounts of precipitation run the full length of the island. Forecasts do not capture the precipitation off the west coast of Sumatra (Fig. 5d), though they still have some precipitation over the ocean, similar to GPM. Three days into the forecast 
precipitation over the ocean is decreased (Fig. $5 \mathrm{~g}$ ) but the precipitation over land is still relatively strong. Examining early morning in the forecasts also shows that precipitation over the ocean around Sumatra decreases following the first day forecast (not shown), explaining the large drop in Malaysia domain precipitation shown in Fig. 2a. By the final day of the forecast precipitation amounts have slightly decreased but 400 the spatial pattern remains the same (Fig. $5 \mathrm{j} ; \mathrm{k} ; \mathrm{l})$

401 To examine how forecast skill depends on the diurnal cycle in the region, the skill of 402 the three ensembles is examined. The shading in Fig. 6 demonstrates eFSS for the 403 standard ensemble forecast, but the eFSS $=0.5$ "skilful threshold" contours are shown 404 for all three forecast variations described in Section 3. Forecasts with skill exceeding 4050.5 , regions to the right of the colored lines in Fig. 6, are considered skilful for the 406 given spatial scale and lead time. Forecasts with lines further to the left in the figure 407 are therefore more skilful at smaller spatial scales.

408 Forecast skill of three-hourly precipitation is strongly tied to the diurnal cycle for the 409 Malaysia forecasts (Fig. 6a) and the Indonesia forecasts (Fig. 6b). The Philippines 410 forecast skill shows some link to the diurnal cycle but this is less pronounced than that 411 of the other two domains (Fig. 6c). Skill tends to be largest in the daytime when 412 precipitation is over land and smallest at night when precipitation is offshore. It is 413 likely that this is due to precipitation that is constrained by topography, and therefore 414 more predictable, during the day. For the first day forecasts are considered skilful at 415 spatial scales greater than approximately $200 \mathrm{~km}$ (Fig. 6). After the first day forecast 416 skill begins to decrease as lead time increases. On day 5 of the forecasts there is skill 417 on spatial scales greater than around $400 \mathrm{~km}$. These scales are comparable to analysis 418 by Dey et al. (2014) that showed skill on scales greater than $200 \mathrm{~km}$ for forecasts of 
extreme rainfall in the UK using a similar nested $2.2 \mathrm{~km}$ ensemble. Woodhams et al.

420 (2018) also find that a deterministic CP model forecast of extreme rainfall over East

421 Africa is skilful at spatial scales around $275-300 \mathrm{~km}$.

422 The reliance of skill on time of day leads to a question: how much of forecast skill is

423 driven simply by diurnal variations? The ensemble forecast is compared with the

424 other two forecast variations described in section 3.2 in order to gain an idea of the

425 role of persisting weather in the forecast skill, and how much value is added by the

426 dynamical ensemble forecast. It is found that the standard ensemble forecast is more

427 skilful than the persistence forecast for all three domains, indicating that the ensemble

428 forecast contains more information about the weather occurring in the future than can

429 be inferred from local knowledge of the diurnal cycle observed on the day before

430 making the forecast.

431 The 'shifted forecast' (see section 3.2) tests how much predictability comes from the

432 characteristics of the diurnal cycle in the current flow regime and season. The

433 standard forecast is substantially more skilful than the shifted forecast in all three

434 domains (Fig. 6). This implies that substantial skill in the precipitation forecast is

435 associated with phenomena with multi-day timescales, or that the forecast is skilfully

436 predicting day-to-day variation in the characteristics of the diurnal cycle which are

437 conditional on the large-scale environment. It is expected that as lead time increases

438 the standard ensemble forecast skill must tend towards the skill of the shifted forecast

439 as the model forecast increasingly becomes no better than a forecast of a different

440 day.

441 Interestingly, for Malaysia (Fig. 6a) and Indonesia (Fig. 6b) the shifted forecast is

442 more skilful than the persistence forecast at all lead times beyond the initial 3 hours. 
443 During the first 24 hours the difference is small. Moving into day 2, the persistence

444 forecast becomes substantially worse than the shifted forecast, implying that the

445 precipitation field has multi-day variability that is captured by the model. This is

446 particularly true for the Philippines (Fig. 6c), which has a large drop in the skill of the

447 persistence forecast following day 1 relative to the model. In conclusion, even at five-

448 days lead time, the ensemble forecast is still more skilful than a forecast based on

449 persistence, as well as the shifted forecasts, that mainly capture the diurnal cycle.

450 Skill is increased when precipitation is located over land, perhaps because it is more

451 constrained by orography. To examine this further, a Localised Fractions Skill Score

452 (LFSS, see section 3.1) can be calculated (Fig. 7). It should be noted that while the red

453 line in Fig. 7 indicates a threshold of 0.5 in keeping with Fig. 6, this should not be

454 considered a threshold of 'skilfulness' in this context. Rather, the LFSS is a tool to

455 understand the distribution of skill across the full domain, in relation to the eFSS.

456 During early evening higher skill tends to be located over land where the forecast has

457 most precipitation, such as in the northwest region of Sumatra (Fig. 7a) and over Java

458 (Fig. 7b). Comparing the spatial patterns of skill to the $95^{\text {th }}$ percentile of precipitation

459 (Fig. 3) shows that the spatial patterns are similar in these regions. There is much less

460 skill over ocean for the Malaysia and Indonesia domains (Fig. 8a;b). Peaks in skill

461 over ocean also tend to be lower than those over land (Fig. 8). This supports the idea

462 that most skill comes from precipitation that is spatially constrained, and results in the

463 diurnal variation of skill as precipitation moves from ocean to land.

464 There are also regions of high skill that have lower $95^{\text {th }}$ percentile rainfall in both

465 GPM and forecasts, such as the north of the Philippines (Fig. 7c). This skill is likely

466 tied to synoptic-scale variability, i.e. tropical cyclones. This region of skill is also 
relatively independent of the diurnal cycle and is still present at other times of day

468 (not shown), supporting this hypothesis.

469 As lead time increases, skill decreases rapidly but is still highest in mountainous

470 regions and in the north of the Philippines (Fig. 7d-i). Localised skill analysis

471 suggests that the diurnal cycle is more important for skill in Malaysia and Indonesia

472 since rainfall is more spatially constrained by orographic features when over land. For

473 the Philippines, skill is more likely to come from synoptic-scale systems that are not

474 as dependent on time of day.

\subsection{Ensemble spread-skill relationship for $4.5 \mathrm{~km}$ forecasts}

476 The dispersion Fractions Skill Score (dFSS; Dey et al. 2014) is used to assess spatial 477 differences between ensemble members, or "ensemble spread", in relation to forecast 478 skill (see section 3.1). If the ensemble is "well calibrated" then the dFSS and eFSS 479 should be the same. If the dFSS is smaller than the eFSS, then the ensemble is over480 spread (under-confident) and if the dFSS is larger than the eFSS, then the ensemble is 481 under-spread (over-confident). For Malaysia forecasts the dFSS is larger than eFSS 482 (Fig. 9a;b) at all lead times and spatial scales, indicating that ensemble members are 483 too similar to one another compared to the difference between the forecasts and 484 observations. This is also true for Indonesia and the Philippines (Fig. 9c-f). Ensembles 485 are under-spread in relation to the skill, and displacement errors in forecast rainfall 486 features are typically larger than the differences between ensemble members. This is 487 consistent with previous studies that find MetUM convective-scale ensembles to be 488 under-spread (Porson et al. 2020, Cafaro et al. 2020), and being under-spread is a 489 common error for CP ensembles generally (Schwartz et al. 2014; Beck et al. 2016; 490 Raynaud and Bouttier 2017). Problems with spread can be linked to model errors (e.g. 
491 Stensrud et al. 2000) and initial conditions and lateral boundary conditions from the 492 parent ensemble. However, finding the underlying cause in this case would require 493 further study.

494 The spread also varies with the diurnal cycle, consistent with the variation in 495 ensemble skill. Ensemble spread is smallest (larger dFSS) during local evening, with 496 dFSS peaking around 8-11pm (lead 12-15), particularly at longer lead times (Fig.

$4979 a ; c ; e)$. Consistent with the skill results discussed previously, this is when 498 precipitation is typically over land and is more spatially constrained, and therefore 499 more similar between ensemble members. When precipitation is over ocean there is 500 slightly more ensemble spread, indicated by reduced dFSS.

\subsection{The role of resolution and convection parameterisation in forecast skill and}

502 spread

503 The $4.5 \mathrm{~km}$ ensembles examined in the earlier sections are part of a larger set of 504 nested ensembles that include ensembles with a 2.2 and $8.8 \mathrm{~km}$ horizontal grid 505 spacing, but the same model levels (see section 2.1), and provide an opportunity to 506 examine the role of resolution in forecast skill. Analysis of an $8.8 \mathrm{~km}$ ensemble with 507 parameterised convection (GA ensemble) is also included to examine how much skill 508 is gained from partially resolving convection with the dynamical core. Resolution 509 tends to play a fairly minor role in forecast skill for all three regions (Fig. 10). This is 510 also the case when using a higher rainfall percentile threshold, such as the $99^{\text {th }}$ 511 percentile (not shown). $2.2 \mathrm{~km} \mathrm{CP}, 4.5 \mathrm{~km} \mathrm{CP}$ and $8.8 \mathrm{~km} \mathrm{CP}$ ensembles all have 512 similar variation in skill as a function of lead time and in this measure the 2.2 and 4.5

$513 \mathrm{~km}$ forecasts are barely distinguishable. This was found to be true evaluating across 514 the range of neighbourhood scales from grid-scale to $288 \mathrm{~km}$ (results are only shown 
515 for $144 \mathrm{~km}$, the smallest scale for which the eFSS exceeds 0.5 for all domains in the 516 first day). During early evening, when skill in the $4.5 \mathrm{~km}$ ensemble (blue line in Fig. 517 10) is highest, the $8.8 \mathrm{~km} \mathrm{CP}$ ensemble (red line) has less skill in the Malaysia domain 518 than the $2.2 \mathrm{~km}$ and $4.5 \mathrm{~km}$ ensembles (Fig. 10a), but in general the differences are

519 small. A possible reason for this is that resolution may be less important at longer lead 520 times where large-scale conditions dominate, and so resolution variations have little 521 effect on skill.

522 There is a larger difference in the skill between the CP ensembles and the GA 523 ensemble (green line in Fig. 10), though this is region dependent. For the Malaysia 524 domain the GA ensemble is less skilful across all lead times, except for the first few 525 hours of forecasts, during the spin-up period (Fig. 10a). Parameterised convection has 526 less effect on skill in the Indonesia domain, though skill peaks earlier in the day 527 compared to the $\mathrm{CP}$ ensemble skill. (Fig. 10b). A note to make here is that the diurnal 528 cycle of precipitation in Malaysia and Indonesia is not as well captured by the GA 529 ensemble (not shown); the observed peaks in rainfall tend to occur a few hours earlier 530 in the GA ensemble, around 6 UTC (early afternoon local time) and 18UTC (early 531 morning local time). The afternoon skill peak therefore coincides with a time when 532 rainfall is increasing in observations and decreasing in the GA ensemble. This peak in 533 skill in the Indonesia domain likely reflects a time when rainfall patterns match better 534 than other times of day, but not for the correct reasons; rainfall in the GA ensemble 535 does not move over ocean during night in the same way as in observations and the CP 536 ensembles (not shown). Since rainfall in the Malaysia and Indonesia domains is 537 largely driven by diurnal variations it is expected that the skill of the GA ensemble is 538 less than the $\mathrm{CP}$ ensembles that capture diurnal variations more accurately. 
539 While there is little difference between the skill in the CP ensembles it is important to 540 note that rainfall is reduced in lower resolution $8.8 \mathrm{~km} \mathrm{CP}$ ensembles (Table 1). Peaks

541 also tend to occur slightly later in the day in these ensembles, particularly for the

542 Malaysia domain, with the early morning peak hardly being captured at all (not

543 shown). This is indicative of larger errors in the diurnal cycle of precipitation in the

544 lower resolution ensembles, despite little difference being shown in the FSS measure

545 of spatial skill. It is therefore important not to consider all CP ensembles to have equal

546 value for operational forecasting despite similar FSS values.

547 In the Philippines domain there is almost no difference in skill between the CP

548 ensembles at all resolutions (Fig. 10c). However, following the first 12 hours of the

549 forecast the GA ensemble has slightly more skill than the CP ensembles, in contrast to

550 the other two regions. A possible reason for this is that precipitation patterns

551 associated with certain, likely larger scale, phenomena are represented more

552 accurately in the GA ensemble. The CP forecasts spin up at initialisation and this may 553 explain the higher skill of the GA model since less spin up may occur from the initial 554 conditions. This is a surprising result since previous studies find that drivers of 555 Philippines rainfall, such as tropical cyclones, can be represented more accurately by 556 CP models (Bousquet et al. 2020). A full analysis of the differences in the 557 representation drivers of rainfall between CP and GA ensembles is outside of the 558 scope of this study, but this result certainly highlights an area of future research.

559 Resolution also has a small impact on ensemble spread (Fig 9d-f). All three CP

560 ensembles are under-spread to a similar degree at the $144 \mathrm{~km}$ neighbourhood scale.

561 Note here that ensemble spread is shown over a sub-region with boundaries 2 degrees 562 away from the $2.2 \mathrm{~km}$ boundaries to avoid a larger influence of lateral boundary 
563 conditions on the $2.2 \mathrm{~km}$ ensemble than the larger domain ensembles. When

564 performing analysis over the full $2.2 \mathrm{~km}$ ensemble domain the spread of the $2.2 \mathrm{~km}$

565 ensemble is smaller than that of the $4.5 \mathrm{~km}$ and $8.8 \mathrm{~km} \mathrm{CP}$ ensembles (not shown) as

566 a result of the role of lateral boundary conditions on ensemble spread. Ensemble

567 spread in the GA ensemble is relatively similar to the CP ensembles at most times of

568 day but reduces during early afternoon (local time; approximately 4 UTC) when

569 observed rainfall is moving from over ocean to over land (Fig. 10d; e). This suggests

570 that the ensemble spread in the spatial patterns of rainfall is much less than the CP

571 ensemble as a result of the parameterisations used. In the Philippines, where rainfall is

572 not as strongly driven by the diurnal cycle, ensemble spread is similar in the GA

573 ensemble and the CP ensembles, particularly during the first two to three days of the

574 forecast.

\section{Summary and Conclusions}

576 Convection-permitting (CP) ensemble forecasts in the Tropics have, until now, been

577 relatively uncommon. Recently, the UK Met Office have developed such systems

578 over Singapore (Porson et al. 2019) and East Africa (Cafaro et al. 2020). Model

579 development has now extended to further domains in Southeast Asia, covering

580 Malaysia, Indonesia and the Philippines. In this study the skill of newly-developed CP

581 ensembles over these regions has been examined using the Fractions Skill Score

582 (FSS), with a particular focus on the role of the diurnal cycle and quantifying the

583 spread of the ensemble in relation to skill.

584 The skill of forecasts of precipitation in the Malaysia and Indonesia domains are

585 strongly linked to the diurnal cycle, peaking during local early evening when rainfall

586 is over land and dropping in local early morning when rainfall is over ocean (Fig. 6). 
587 The diurnal variation suggests that orographic and coastal features play a role in skill,

588 such that precipitation over mountainous regions is spatially constrained and therefore

589 better captured by the model. Land-sea contrast is also important to the characteristics

590 of the rainfall. Examination of maps of the Localised Fractions Skill Score (LFSS)

591 confirms this, as the largest skill tends to be over mountainous regions and skill is

592 much lower over the ocean (Fig. 7; Fig. 8). The diurnal cycle is less strong in the

593 Philippines domain, suggesting that other modes of variability drive precipitation

594 there. Skill decreases as lead time increases, and forecasts are skilful at spatial scales

595 greater than $400 \mathrm{~km}$ for all lead times and all domains, providing a suggested scale for

596 future forecast display.

597 The large role played by the diurnal cycle motivates the question as to how much of

598 the skill is potentially predictable simply by representing well the diurnal cycle in the 599 region. Vogel et al. (2018) found that forecasts of precipitation in West Africa that

600 were based on climatological precipitation outperformed operational ensemble

601 forecasts that used parameterised convection schemes. Here, comparisons are made to

602 persistence forecasts to examine how the $\mathrm{CP}$ ensembles perform relative to a forecast

603 from recently observed rainfall. In this case all three ensembles have much higher

604 skill than a persistence forecast, suggesting that there is significant added value in the

$605 \mathrm{CP}$ ensemble compared to a forecast based on observed rainfall from the previous

606 day. Skill for a 'shifted forecast', in which the forecast date stamps are shifted one

607 day later and therefore verified against observations from one day after the true

608 verification date, is also presented to determine how much of the model skill is related

609 to simulation of the diurnal cycle. The skill of the shifted forecast is larger than the

610 persistence forecast, but less than the standard ensemble forecast, for lead times

611 longer than one day. This suggests that increased CP ensemble forecast skill is 
associated with phenomena characterised by multi-day timescales that are captured by

613 the model, highlighting the usefulness of the $\mathrm{CP}$ ensemble in this region.

614 Variation of horizontal grid spacing, across $2.2,4.5$ and $8.8 \mathrm{~km}$, plays a fairly small

615 role in ensemble skill assessed using the Fractions Skill score over the full range of

616 neighbourhood scales. These results agree with previous studies that also find $1-2 \mathrm{~km}$

617 resolution forecasts rainfall in the United States to perform as well as $4 \mathrm{~km}$ forecasts

618 (Kain et al. 2008; Schwarz et al 2009; Loken et al. 2017). However, other studies

619 found that increased resolution resulted in higher forecast skill for United States

620 rainfall (Schwarz et al. 2017; Shwartz and Sobash 2019). Schwartz and Sobash (2019)

621 suggest that this could be because of higher quality initial conditions than in previous

622 studies. Given the computational cost of higher resolution forecasts this is a result to

623 be considered in future forecast model development focussing on this region

624 The $8.8 \mathrm{~km}$ GA ensemble using a parameterised convection scheme has less skill 625 compared to the $\mathrm{CP}$ ensembles, but only in the regions where rainfall patterns are 626 strongly driven by the diurnal cycle, i.e. Malaysia and Indonesia. In the Philippines 627 region, $\mathrm{CP}$ ensembles have slightly lower skill than the GA ensemble suggesting that 628 CP forecasts add limited value when forecasting spatial patterns of rainfall in the 629 Philippines region. This is likely due to the higher latitude location of the Philippines 630 and hence stronger synoptic scale forcing of rainfall and weaker dependence on local 631 thermal contrasts in forcing convective systems. Also, there are no additional high632 resolution observations assimilated into the $\mathrm{CP}$ forecasting system and the initial 633 conditions for each forecast member are obtained simply by interpolating the parent 634 global member onto a finer grid. The only benefit that could come from the higher 635 resolution is an improvement in the representation of the lower boundary and weather 
636 system dynamics. The higher resolution forecasts need to spin up and this may

637 explain the apparently higher skill of the $8.8 \mathrm{~km}$ model with parameterised

638 convection, rather than explicit. The model dynamics with parameterisation is more

639 similar to the global model parent and therefore less spin up may occur from the

640 initial conditions. An important note and caveat to make here is that while resolution

641 plays a small role in skill measured using the FSS there are many other reasons why a

642 higher-resolution model is preferable. Other aspects of rainfall, aside from spatial

643 pattern, such as intensity and timing, are of importance and should be considered

644 when choosing models for an operational forecast.

645 The spread of the ensemble is examined using the dispersion Fractions Skill Score

646 (dFSS), which compares ensemble member pairs to obtain a measure of the spatial

647 differences within the ensemble. Spread also varies with the diurnal cycle such that

648 there is less ensemble spread when precipitation is over land, again supporting the

649 idea that convection is more constrained by orography at that time (Fig. 9). The

650 ensemble is under-dispersive. Spread is $59 \%, 61 \%$ and $33 \%$ less than ensemble mean

651 forecast error on average over $4.5 \mathrm{~km}$ forecasts for Malaysia, Indonesia, and

652 Philippines domains respectively, confirming that these ensembles suffer from a

653 persistent drawback of CP ensembles. While using percentiles for the threshold choice

654 in calculations (rather than a fixed amount threshold) somewhat counteracts the

655 influence of rainfall intensity bias, there are further possible causes of reduced

656 ensemble spread, such as the influence of initial and lateral boundary conditions and

657 model errors. Studies have found various ways to improve ensemble spread, such as

658 combining ensembles (Beck et al. 2016) and time-lagging ensemble member forecasts

659 (Porson et al. 2020). Porson et al. (2019) assessed the difference in skill and spread in

660 an ensemble covering Singapore nested in two different global ensembles. They find 
661 that spread is sensitive to initial conditions at the beginning of the forecast and lateral

662 boundary conditions towards the end of the forecast. While beyond the scope of the

663 present study, investigating why the ensembles analysed here are under-spread would

664 be an interesting topic of future research. Assimilation of high resolution data to

665 generate a higher resolution regional analysis would be expected to improve initial

666 conditions for the CP ensembles, introducing spread associated with observed

667 mesoscale features and acting to reduce artificial forecast spin up effects which may

668 reduce skill. However, assimilation in the convection-dominated regime in the tropics

669 is challenging, due to convective instability and the high variance on small spatial and

670 temporal scales, and prototype systems assimilating satellite radiance data are

671 currently under development in the Southeast Asia region (Heng et al. 2020).

672 Despite the lack of sufficient spread in the CP ensembles shown here, the forecasts

673 have significant skill beyond that shown by a persistence forecast based on observed

674 climatology. Aside from improvements to ensemble spread, future work with these

675 forecasts should focus on sources of skill in the three different regions, including the

676 role of large-scale conditions in forecast skill. Understanding drivers of forecast skill

677 will lead to improved forecasts of high-impact weather in the region and should

678 therefore be a high priority in future.

680 Acknowledgements

681 This work and SF, THAF, CEH, JM and THMS were supported by the Weather and

682 Climate Science for Services Partnership (WCSSP) Southeast Asia as part of the

683 Newton Fund. We thank three anonymous reviewers for insightful comments and

684 suggestions on this work. The GPM-IMERG data were provided by the NASA 
685 Goddard Space Flight Center's Precipitation Measurement Missions Science Team

686 and Precipitation Processing System, which develop and compute GPM-IMERG as a 687 contribution to GPM, and archived at the NASA GES DISC. 
688

689

690

691

692

693

694

695

696

697

698

699

700

701

702

703

704

705

706

707

708

\section{$\underline{\text { References }}$}

Beck, J., F. Bouttier, L. Wiegand, C. Gebhardt, C. Eagle, and N. Roberts, 2016:

Development and verification of two convection-allowing multi-model ensembles over Western Europe. Q. J. R. Meteorol. Soc., 142, 2808-2826, https://doi.org/10.1002/qj.2870.

Bednarczyk, C. N., and B. C. Ancell, 2015: Ensemble sensitivity analysis applied to a southern plains convective event. Mon. Weather Rev., 143, 230-249, https://doi.org/10.1175/MWR-D-13-00321.1.

Birch, C. E., J. H. Marsham, D. J. Parker, and C. M. Taylor, 2014a: The scale dependence and structure of convergence fields preceding the initiation of deep convection. Geophys. Res. Lett., 41, 4769-4776, https://doi.org/10.1002/2014GL060493.

— D. J. Parker, J. H. Marsham, D. Copsey, and L. Garcia-Carreras, 2014b: A seamless assessment of the role of convection in the water cycle of the West African Monsoon. J. Geophys. Res. Atmos., 119, 2890-2912, https://doi.org/10.1002/2013JD020887.

—, M. J. Roberts, L. Garcia-Carreras, D. Ackerley, M. J. Reeder, A. P. Lock, and R. Schiemann, 2015: Sea-breeze dynamics and convection initiation: The influence of convective parameterization in weather and climate model biases. $J$. Clim., 28, 8093-8108, https://doi.org/10.1175/JCLI-D-14-00850.1. , and Coauthors, 2016: Scale Interactions between the MJO and the Western 

$\underline{15-0557.1 .}$

712

713

714

Bousquet, O, D. Barbary, S. Bielli, and Coauthors. 2020 An evaluation of tropical cyclone forecast in the Southwest Indian Ocean basin with AROME-Indian Ocean convection-permitting numerical weather predicting system. Atmos Sci Lett. 21:e950. https://doi.org/10.1002/as12.950

Bowler N, A. Arribas, K. Mylne, K. Robertson, S. Beare. 2008. The MOGREPS short-range ensemble prediction system. Q. J. R. Meteorol. Soc. 134:703-72

Bush, M., and Coauthors. 2020: The first Met Office Unified Model-JULES Regional Atmosphere and Land configuration, RAL1, Geosci. Model Dev., 13, 1999-2029, https://doi.org/10.5194/gmd-13-1999-2020.

Cafaro, C., T. H. A. Frame, J. Methven, N. Roberts,. and J. Bröcker, 2019. The added value of convection-permitting ensemble forecasts of sea breeze compared to a Bayesian forecast driven by the global ensemble. Q. J. R. Meteorol. Soc., 145(721), 1780-1798.

Cafaro, C., and Coauthors, 2020: Do convection-permitting ensembles lead to more skillful short-range probabilistic rainfall forecasts over tropical East Africa?, Wea. Forecasting, under review.

Chang, C. P., P. A. Harr, and H. J. Chen, 2005: Synoptic disturbances over the equatorial South China Sea and western maritime continent during boreal winter. Mon. Weather Rev., 133, 489-503, https://doi.org/10.1175/MWR-2868.1.

Clark, P., N. Roberts, H. Lean, S. P. Ballard, and C. Charlton-Perez, 2016: 
Convection-permitting models: A step-change in rainfall forecasting. Meteorol. Appl., 23, 165-181, https://doi.org/10.1002/met.1538.

De Silva, N., and Coauthors, 2021: Validation of GPM IMERG extreme precipitation in the Maritime Continent by station and radar data (In Preparation)

Dey, S. R. A., G. Leoncini, N. M. Roberts, R. S. Plant, and S. Migliorini, 2014: A spatial view of ensemble spread in convection permitting ensembles. Mon. Weather Rev., 142, 4091-4107, https://doi.org/10.1175/MWR-D-14-00172.1.

Dipankar, A., and coauthors, 2020: SINGV: A convective-scale weather forecast model for Singapore. $Q J$ R Meteorol Soc. 1 - 16. https://doi.org/10.1002/qj.3895

Ferrett, S., G. Yang, S. J. Woolnough, J. Methven, K. Hodges, and C. E. Holloway, 2020: Linking extreme precipitation in Southeast Asia to equatorial waves. Q. J. R. Meteorol. Soc., 146, 665-684, https://doi.org/10.1002/qj.3699.

Gebhardt C., S.E. Theis, M. Paulat, Z. Ben Bouallègue, 2011: Uncertainties in COSMO-DE precipitation forecasts introduced by model perturbations and variation of lateral boundaries, Atmospheric Research, 100, 168-177, https://doi.org/10.1016/j.atmosres.2010.12.008.

Golding, B. W., and Coauthors, 2014: Forecasting Capabilities for the London 2012 Olympics. Bull. Amer. Meteor. Soc., 95, 883-896, https://doi.org/10.1175/BAMS-D-13-00102.1.

Hagelin, S., J. Son, R. Swinbank, A. McCabe, N. Roberts and W. Tennant, 2017: The Met Office convective-scale ensemble, MOGREPS-UK. Q.J.R. Meteorol. Soc., 143: 2846-2861. doi:10.1002/qj.3135 
Hamada, J.-I., S. Mori, H. Kubota, M. D. Yamanaka, U. Haryoko, S. Lestari, R. Sulistyowati, and F. Syamsudin, 2012: Interannual Rainfall Variability over Northwestern Jawa and its Relation to the Indian Ocean Dipole and El $\left.\mathrm{Ni}^{\wedge}\right|^{\wedge}$ ntilde;o-Southern Oscillation Events. SOLA, 8, 69-72, https://doi.org/10.2151/sola.2012-018.

Hanley, K. E., D. J. Kirshbaum, N. M. Roberts, and G. Leoncini, 2013: Sensitivities of a Squall Line over Central Europe in a Convective-Scale Ensemble. Mon. Weather Rev., 141, 112-133, https://doi.org/10.1175/MWR-D-12-00013.1.

Heng, B. C. P, and Coauthors, 2020: SINGV-DA: A data assimilation system for convective-scale numerical weather prediction over Singapore. $Q J R$ Meteorol Soc., 146, 1923- 1938, https://doi.org/10.1002/qj.3774

Hohenegger, C., and C. Schar, 2007: Atmospheric Predictability at Synoptic Versus Cloud-Resolving Scales. Bull. Amer. Meteor. Soc., 88, 1783-1794, https://doi.org/10.1175/BAMS-88-11-1783.

Holloway, C. E., S. J. Woolnough, and G. M. S. Lister, 2013: The effects of explicit versus parameterized convection on the MJO in a large-domain high-resolution tropical case study. Part I: Characterization of large-scale organization and propagation. J. Atmos. Sci., 70, 1342-1369, https://doi.org/10.1175/JAS-D-120227.1.

Huffman, G. J., and Coauthors, 2019: NASA Global Precipitation Measurement (GPM) Integrated Multi-satellitE Retrievals for GPM (IMERG), Algorithm Theoretical Basis Document (ATBD), Version 06. 38 pp. https://gpm.nasa.gov/sites/default/files/document_files/IMERG_ATBD_V06.pdf 
Johnson, S. J., and Coauthors, 2016: The resolution sensitivity of the South Asian monsoon and Indo-Pacific in a global $0.35^{\circ}$ AGCM. Clim. Dyn., 46, 807-831, https://doi.org/10.1007/s00382-015-2614-1.

Kain, J. S., Weiss, S. J., Bright, D. R., Baldwin, M. E., Levit, J. J., Carbin, G. W., Schwartz, C. S., Weisman, M. L., Droegemeier, K. K., Weber, D. B., \& Thomas, K. W. 2008: Some Practical Considerations Regarding Horizontal Resolution in the First Generation of Operational Convection-Allowing NWP, Weather and Forecasting, 23(5), 931-952

Khan, S. and V. Maggioni, 2019: Assessment of Level-3 Gridded Global Precipitation Mission (GPM) Products Over Oceans. Remote Sens, 11, 255.

Kendon, E. J., N. M. Roberts, C. A. Senior, and M. J. Roberts, 2012: Realism of rainfall in a very high-resolution regional climate model. J. Clim., 25, 57915806, https://doi.org/10.1175/JCLI-D-11-00562.1.

Lestari, S., A. King, C. Vincent, D. Karoly, and A. Protat, 2019: Seasonal dependence of rainfall extremes in and around Jakarta, Indonesia. Weather Clim. Extrem., 24, 100202, https://doi.org/10.1016/j.wace.2019.100202.

Lim, S. Y., C. Marzin, P. Xavier, C. P. Chang, B. Timbal, S. Yee Lim, C. Marzin, and P. Xavier, 2017: Impacts of Boreal Winter Monsoon Cold Surges and the Interaction with MJO on Southeast Asia Rainfall. J. Clim., 30, 4267-4281, https://doi.org/10.1175/JCLI-D-16-0546.1.

Lin, J. L., and Coauthors, 2006: Tropical intraseasonal variability in 14 IPCC AR4 climate models. Part I: Convective signals. J. Clim., 19, 2665-2690, https://doi.org/10.1175/JCLI3735.1. 
Loken, E. D., Clark, A. J., Xue, M., and Kong, F. 2017: Comparison of Next-Day Probabilistic Severe Weather Forecasts from Coarse- and Fine-Resolution CAMs and a Convection-Allowing Ensemble, Weather and Forecasting, 32(4), $1403-1421$

Love, B. S., A. J. Matthews, and G. M. S. Lister, 2011: The diurnal cycle of precipitation over the Maritime Continent in a high-resolution atmospheric model. Q. J. R. Meteorol. Soc., 137, 934-947, https://doi.org/10.1002/qj.809.

Matsumoto, J., and Coauthors, 2017: An overview of the Asian Monsoon Years 20072012 (AMY) and multi-scale interactions in the extreme rainfall events over the Indonesian maritime continent. World Scientific Series on Asia-Pacific Weather and Climate, Vol. Volume 9 of, World Scientific Publishing Co. Pte Ltd, 365385.

Met Office, 2010-2020: Iris: A Python library for analysing and visualising meteorological and oceanographic data sets; v2.4, http://scitools.org.uk/

Miura, H., M. Satoh, T. Nasuno, A. T. Noda, and K. Oouchi, 2007: A Madden-Julian oscillation event realistically simulated by a global cloud-resolving model. Science (80-. )., 318, 1763-1765, https://doi.org/10.1126/science.1148443.

Mittermaier, M., N. Roberts, and S. A. Thompson, 2013; A long-term assessment of precipitation forecast skill using the Fractions Skill Score. Meteor. Appl. 20, 176186, https://doi.org/10.1002/met.296

Mohd Nor, M. F. F., C. E. Holloway, and P. M. Inness, 2020: The Role of Local Orography on the Development of a Severe Rainfall Event over Western Peninsular Malaysia: A Case Study. Mon. Wea. Rev., 148, 2191-2209, 
Mori, S., H. Jun-Ichi, M. D. Yamanaka, N. Okamoto, F. Murata, N. Sakurai, and H. Hashiguchi, 2004: Diurnal Land-Sea Rainfall Peak Migration over Sumatera Island, Indonesian Maritime Continent, Observed by TRMM Satellite and Intensive Rawinsonde Soundings. American Meteorological Society, 2021-2039 pp.

Neale, R., and J. Slingo, 2003: The Maritime Continent and Its Role in the Global Climate: A GCM Study. American Meteorological Society, 834-848 pp.

Pearson, K. J., R. J. Hogan, R. P. Allan, G. M. S. Lister, and C. E. Holloway, 2010: Evaluation of the model representation of the evolution of convective systems using satellite observations of outgoing longwave radiation. J. Geophys. Res., 115, D20206, https://doi.org/10.1029/2010JD014265.

—, G. M. S. Lister, C. E. Birch, R. P. Allan, R. J. Hogan, and S. J. Woolnough, 2014: Modelling the diurnal cycle of tropical convection across the 'grey zone.' Q. J. R. Meteorol. Soc., 140, 491-499, https://doi.org/10.1002/qj.2145.

Peatman, S. C., A. J. Matthews, and D. P. Stevens, 2014: Propagation of the MaddenJulian Oscillation through the Maritime Continent and scale interaction with the diurnal cycle of precipitation. Q. J. R. Meteorol. Soc., 140, 814-825, https://doi.org/10.1002/qj.2161.

Peatman, S. C., Methven, J. and Woolnough, S. J., 2018: Isolating the effects of moisture entrainment on convectively coupled equatorial waves in an aquaplanet GCM. J. Atmos. Sci., 75, 3139-3157. https://doi.org/10.1175/JAS-D-18-0098.1. 
845

846

847

848

849

850

851

852

854

855

856

857

858

859

860

861

862

863

864

865

866

,-- , and - , 2015: Propagation of the Madden-Julian Oscillation and scale interaction with the diurnal cycle in a high-resolution GCM. Clim. Dyn., 45, 2901-2918, https://doi.org/10.1007/s00382-015-2513-5.

Porson, A. N., S. Hagelin, D. F. A. Boyd, N. M. Roberts, R. North, S. Webster, and J. C. Lo, 2019: Extreme rainfall sensitivity in convective-scale ensemble modelling over Singapore. Q. J. R. Meteorol. Soc., 145, 3004-3022, https://doi.org/10.1002/qj.3601.

— , and Coauthors, 2020: Recent upgrades to the Met Office convective-scale ensemble: An hourly time-lagged 5-day ensemble. Q. J. R. Meteorol. Soc., qj.3844, https://doi.org/10.1002/qj.3844.

Qian, J. H., 2008: Why precipitation is mostly concentrated over islands in the maritime continent. J. Atmos. Sci., 65, 1428-1441, https://doi.org/10.1175/2007JAS2422.1.

Raynaud, L., and F. Bouttier, 2017: The impact of horizontal resolution and ensemble size for convective-scale probabilistic forecasts. Q. J. R. Meteorol. Soc., 143, 3037-3047, https://doi.org/10.1002/qj.3159.

Rezacova, D., P. Zacharov, and Z. Sokol, 2009: Uncertainty in the area-related QPF for heavy convective precipitation. Atmos. Res., 93, 238-246, https://doi.org/10.1016/j.atmosres.2008.12.005.

Roberts, B., I. L. Jirak, A. J. Clark, S. J. Weiss, and J. S. Kain, 2019: Postprocessing and visualization techniques for convection-allowing ensembles. Bull. Amer. Meteor. Soc., 100, 1245-1258. 
Roberts, N. M., and H. W. Lean, 2008: Scale-selective verification of rainfall accumulations from high-resolution forecasts of convective events. Mon. Weather Rev., 136, 78-97, https://doi.org/10.1175/2007MWR2123.1.

Sato, T., H. Miura, M. Satoh, Y. N. Takayabu, and Y. Wang, 2009: Diurnal cycle of precipitation in the tropics simulated in a global cloud-resolving model. J. Clim., 22, 4809-4826, https://doi.org/10.1175/2009JCLI2890.1.

Schwartz, C. S., Kain, J. S., Weiss, S. J., Xue, M., Bright, D. R., Kong, F., Thomas, K. W., Levit, J. J., \& Coniglio, M. C. 2009: Next-Day Convection-Allowing WRF Model Guidance: A Second Look at 2-km versus 4-km Grid Spacing, Monthly Weather Review, 137(10), 3351-3372

Schwartz, C. S., G. S. Romine, K. R. Smith, and M. L. Weisman, 2014: Characterizing and optimizing precipitation forecasts from a convectionpermitting ensemble initialized by a mesoscale ensemble kalman filter. Weather Forecast., 29, 1295-1318, https://doi.org/10.1175/WAF-D-13-00145.1.

Schwartz, C. S., G. S. Romine, R. A. Sobash, K. R. Fossell, and M. L. Weisman, 2015: NCAR's Experimental Real-Time Convection-Allowing Ensemble Prediction System. Wea. Forecasting, 30, 1645-1654, https://doi.org/10.1175/WAF-D-15-0103.1.

Schwartz, C. S., G. S. Romine, K. R. Fossell, A. Sobash, and M. L. Weisman. 2017: Toward 1-km Ensemble Forecasts over Large Domains, Monthly Weather Review, 145(8), 2943-2969 
888

889

890

891

892

894

895

896

897

898

899

900

901

902

903

904

905

906

907

908

909

Schwartz, C. S., and R. A. Sobash 2019: Revisiting Sensitivity to Horizontal Grid Spacing in Convection-Allowing Models over the Central and Eastern United States, Monthly Weather Review, 147(12), 4411-4435

Stensrud, D. J., J. Bao, and T. T. Warner, 2000: Using Initial Condition and Model Physics Perturbations in Short-Range Ensemble Simulations of Mesoscale Convective Systems, Monthly Weather Review, 128(7), 2077-2107

Sun, X., and Coauthors, 2020: A subjective and objective evaluation of model forecasts of sumatra squall events. Weather Forecast., 35, 489-506, https://doi.org/10.1175/WAF-D-19-0187.1.

Supari, F. Tangang, E. Salimun, E. Aldrian, A. Sopaheluwakan, and L. Juneng, 2018: ENSO modulation of seasonal rainfall and extremes in Indonesia. Clim. Dyn., 51, 2559-2580, https://doi.org/10.1007/s00382-017-4028-8.

Takahashi, H. G., and T. Yasunari, 2008: Decreasing Trend in Rainfall over Indochina during the Late Summer Monsoon: Impact of Tropical Cyclones, $J$. Meteorol. Soc. Jpn., 86, 429-438

Tan, M.L. and Z. Duan, 2017: Assessment of GPM and TRMM Precipitation Products over Singapore. Remote Sens., 9, 720.

Tan, M.L. and H. Santo, 2018: Comparison of GPM IMERG, TMPA 3B42 and PERSIANN-CDR satellite precipitation products over Malaysia. Atmos. Res., 202, 63-76.

Tan, J., Huffman, G. J., Bolvin, D. T., \& Nelkin, E. J. 2019: Diurnal cycle of IMERG V06 precipitation. Geophysical Research Letters, 46, 13584- 13592. 
911 Villafuerte, M. Q., and J. Matsumoto, 2015: Significant influences of global mean temperature and ENSO on extreme rainfall in Southeast Asia. J. Clim., 28, 19051919, https://doi.org/10.1175/JCLI-D-14-00531.1.

914 Vincent, C. L., and T. P. Lane, 2018: Mesoscale variation in diabatic heating around 915 Sumatra, and its modulation with the Madden-Julian oscillation. Mon. Weather 916 Rev., 146, 2599-2614, https://doi.org/10.1175/MWR-D-17-0392.1.

917 Vogel, P., P. Knippertz, A. H. Fink, A. Schlueter, and T. Gneiting, 2018: Skill of 918 global raw and postprocessed ensemble predictions of rainfall over Northern 919 Tropical Africa. Weather Forecast., 33, 369-388, https://doi.org/10.1175/WAF$920 \quad$ D-17-0127.1.

921 Wang, J., Chen, J., Du, J., Zhang, Y., Xia, Y., \& Deng, G., 2018: Sensitivity of 922 Ensemble Forecast Verification to Model Bias, Mon. Weather Rev., 146, 781$923 \quad 796$

924 Wilson, D. R., A. C. Bushell, A. M. Kerr-Munslow, J. D. Price, and C. J. Morcrette, 925 2008: PC2: A prognostic cloud fraction and condensation scheme. I: Scheme 926 description, Q. J. Roy. Meteor. Soc., 134, 2093-2107,

928 Woodhams, B. J., C. E. Birch, J. H. Marsham, C. L. Bain, N. M. Roberts, and D. F. A. 929 Boyd, 2018: What is the added value of a convection-permitting model for 930 forecasting extreme rainfall over tropical East Africa? Mon. Weather Rev., 146, 2757-2780, https://doi.org/10.1175/MWR-D-17-0396.1. 
932 Wu, P., M. Hara, J. Hamada, M. D. Yamanaka, and F. Kimura, 2009: Why a Large 933 Amount of Rain Falls over the Sea in the Vicinity of Western Sumatra Island 934 during Nighttime. J. Appl. Meteor. Climatol., 48, 1345-1361, 935 https://doi.org/10.1175/2009JAMC2052.1.

936 Wu, P., A. A. Arbain, S. Mori, J. Hamada, M. Hattori, F. Syamsudin, and M. D. 937 Yamanaka, 2013: The Effects of an Active Phase of the Madden-Julian 938 Oscillation on the Extreme Precipitation Event over Western Java Island in 939 January 2013. SOLA, 9, 79-83, https://doi.org/10.2151/sola.2013-018.

940 Xavier, P., R. Rahmat, W. K. Cheong, and E. Wallace, 2014: Influence of Madden941 Julian Oscillation on Southeast Asia rainfall extremes: Observations and 942 predictability. Geophys. Res. Lett., 41, 4406-4412, 943 https://doi.org/10.1002/2014GL060241.

944 Yamanaka, M. D., 2016: Physical climatology of Indonesian maritime continent: An 945 outline to comprehend observational studies. Atmos. Res., 178-179, 231-259, 946 https://doi.org/10.1016/j.atmosres.2016.03.017.

947 Yang, G.-Y., and J. Slingo, 2001: The Diurnal Cycle in the Tropics. American $948 \quad$ Meteorological Society, 784-801 pp. 


\begin{tabular}{l|l|l|l} 
Region & $\begin{array}{l}\text { GPM/model } \\
\text { resolution }\end{array}$ & $95^{\text {th }} \mathrm{pc}$ & $99^{\text {th }} \mathrm{pc}$ \\
\hline \multirow{4}{*}{ Malaysia } & GPM & 1.85 & 5.62 \\
\cline { 2 - 4 } & 2.2 & 1.49 & 7.13 \\
\cline { 2 - 4 } & 4.5 & 0.78 & 6.45 \\
\cline { 2 - 4 } & 8.8 & 0.62 & 6.04 \\
\cline { 2 - 4 } & $8.8(\mathrm{GA})$ & 1.41 & 2.78 \\
\hline Indonesia & GPM & 1.35 & 4.76 \\
\cline { 2 - 4 } & 2.2 & 0.52 & 5.69 \\
\cline { 2 - 4 } & 4.5 & 0.48 & 5.87 \\
\cline { 2 - 4 } & 8.8 & 0.12 & 4.21 \\
\cline { 2 - 4 } & $8.8(\mathrm{GA})$ & 1.23 & 2.57 \\
\hline Philippines & GPM & 0.34 & 2.66 \\
\cline { 2 - 4 } & 2.2 & 0.18 & 3.21 \\
\cline { 2 - 4 } & 4.5 & 0.27 & 4.34 \\
\cline { 2 - 4 } & 8.8 & 0.11 & 2.93 \\
\cline { 2 - 4 } & $8.8(\mathrm{GA})$ & 0.58 & 2.19
\end{tabular}

952 Table 1: The average over all lead times of $95^{\text {th }}$ and $99^{\text {th }}$ percentiles for 3-hourly 953 accumulations of GPM and $2.2 \mathrm{~km} \mathrm{CP,} 4.5 \mathrm{~km} \mathrm{CP,} \mathrm{8.8km} \mathrm{CP,} \mathrm{8.8km} \mathrm{GA} \mathrm{forecasts} \mathrm{for}$ 954 all three regions (using $2.2 \mathrm{~km}$ domains in Fig. 1). All values are converted to rain 955 rate in $\mathrm{mm} \mathrm{hr}^{-1}$.

956 


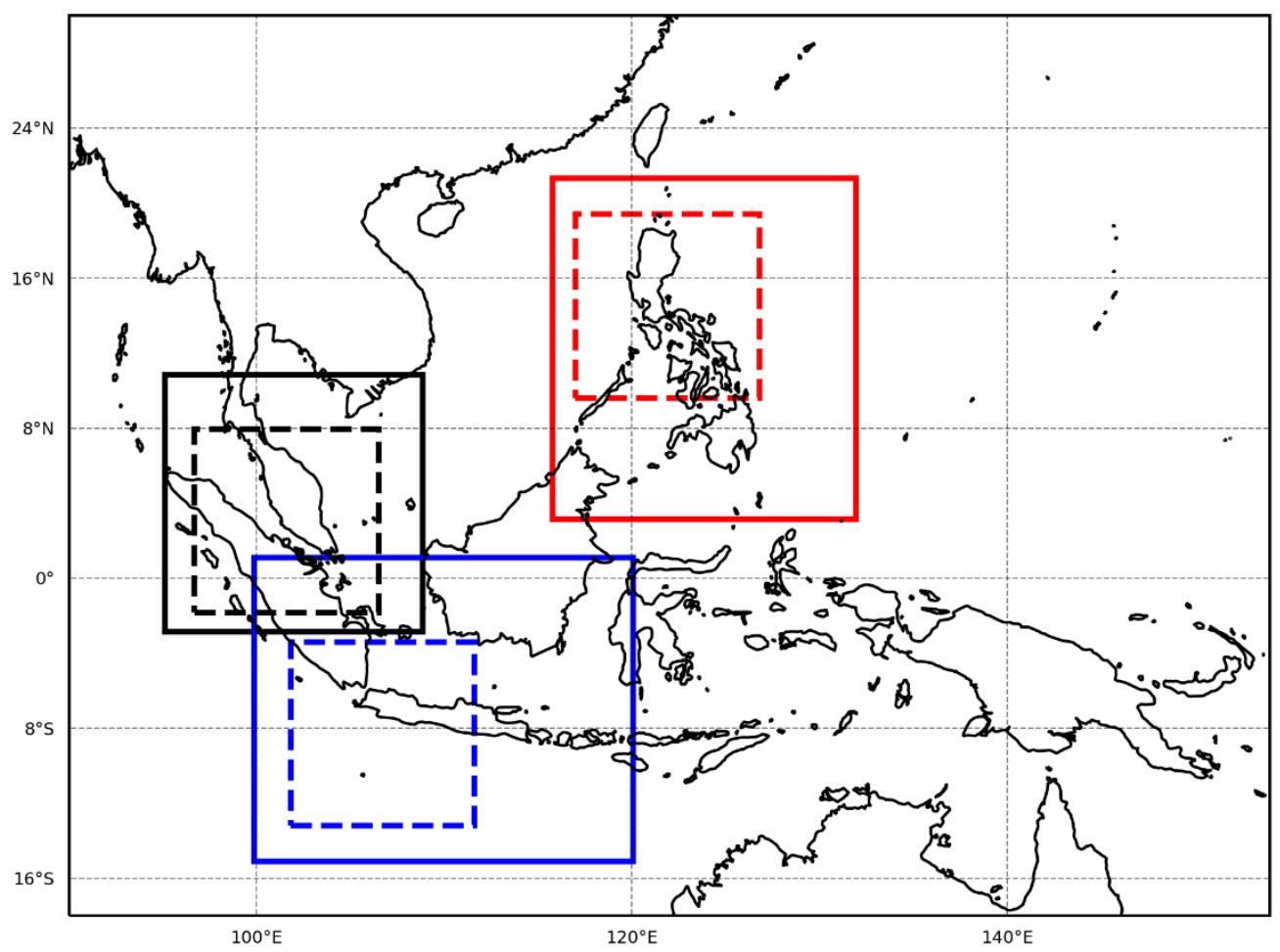

Figure 1: Malaysia (black boxes), Indonesia (blue boxes) and Philippines (red boxes)

960 forecast domains for $2.2 \mathrm{~km}$ forecasts (dashed lines) and $4.5 \mathrm{~km}$ forecasts (solid

961 lines). The full domain shows the $8.8 \mathrm{~km}$ domain. For analysis, the $8.8 \mathrm{~km}$ forecasts are subset to the relevant smaller regional domains. 
a) 95 th percentile ( $24 \mathrm{hr})$
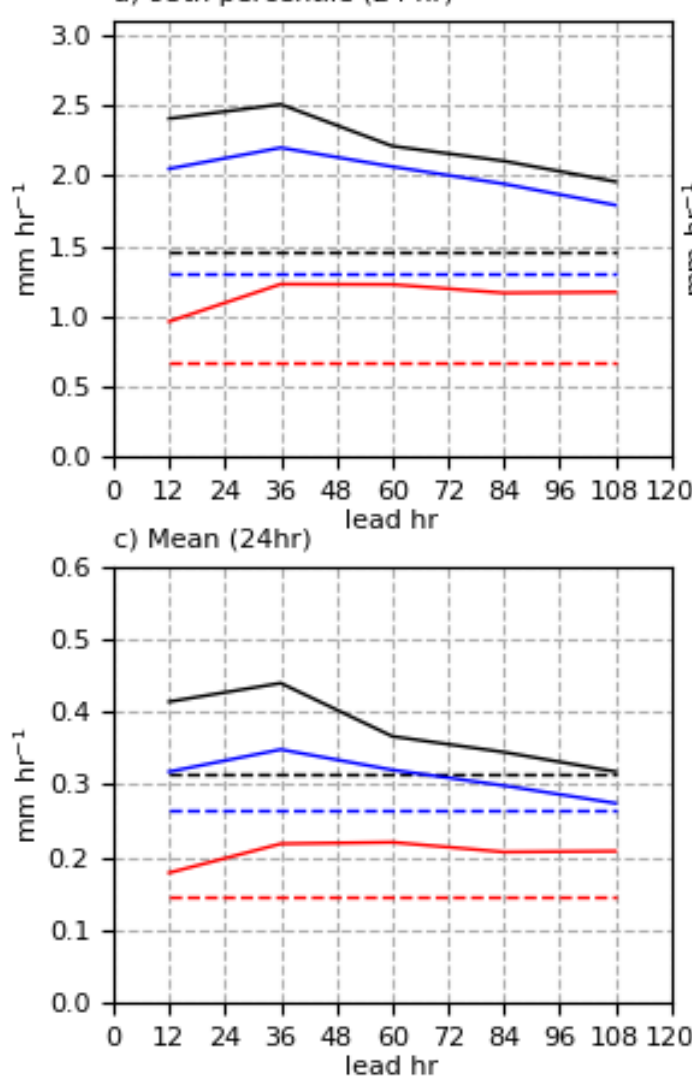

b) 95 th percentile $(3 \mathrm{hr}$ )

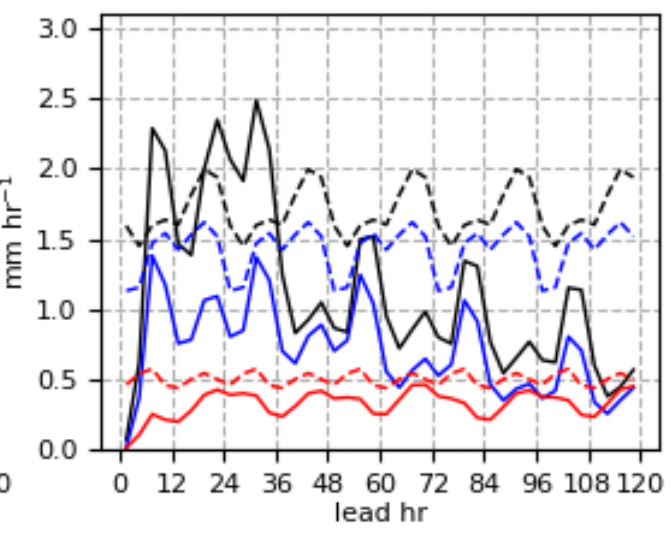

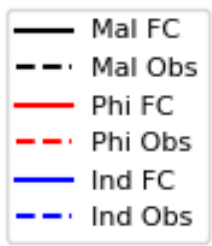

Figure 2: GPM-IMERG (dashed lines) and $4.5 \mathrm{~km}$ forecast (solid lines) $95^{\text {th }}$

965 percentile for a) 24-hourly accumulations, b) 3-hourly accumulations and c) mean of

966 24-hourly precipitation accumulations as a function of forecast lead time. All values

967 are converted to rain rate in $\mathrm{mm} \mathrm{hr}^{-1}$. Values shown here are the thresholds used for

968 FSS calculation (see section 3). For forecasts the percentile are calculated over all

969 ensemble members, all forecasts and all gridpoints in the domain. 

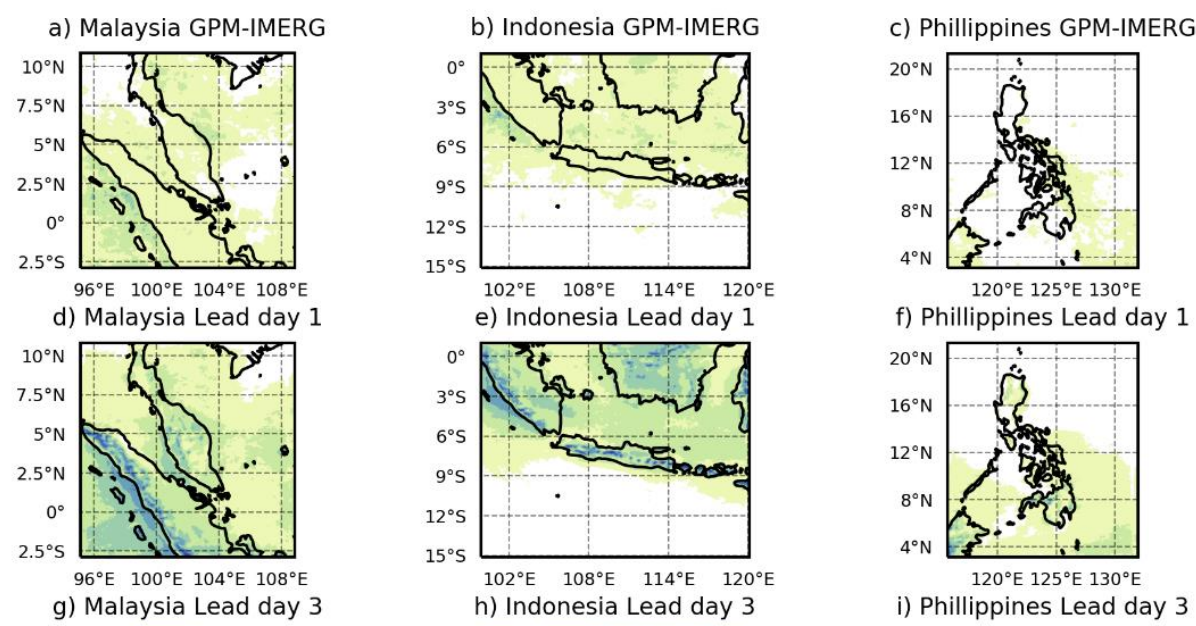

f) Phillippines Lead day 1
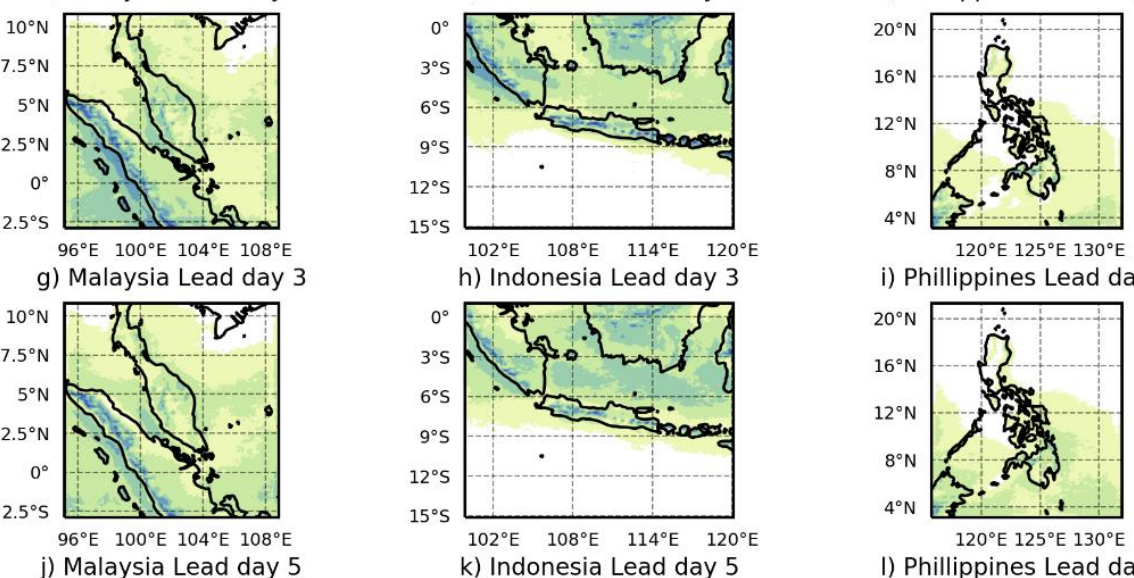

i) Phillippines Lead day 3
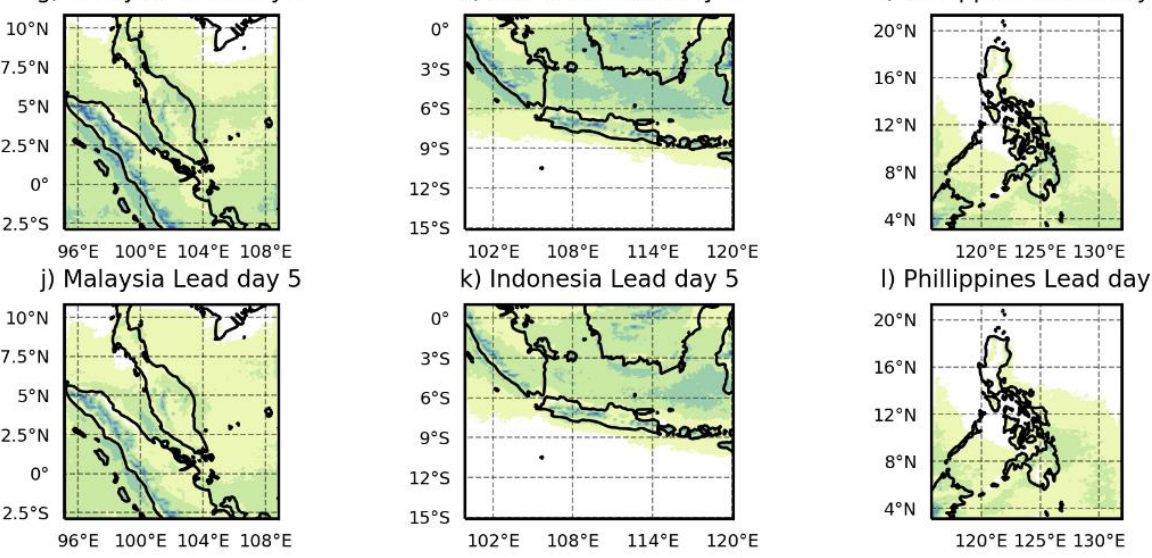

I) Phillippines Lead day 5
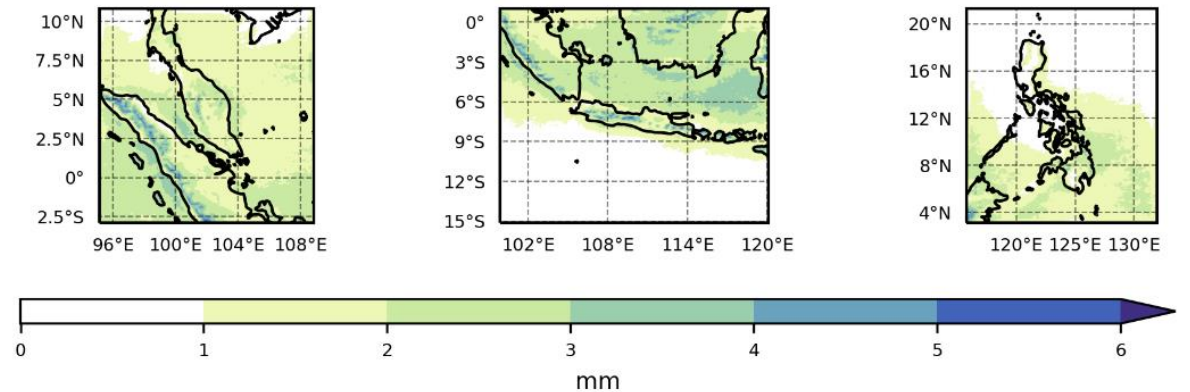

972 Figure 3: GPM-IMERG and $4.5 \mathrm{~km}$ forecast $95^{\text {th }}$ percentile precipitation for

973 Malaysia (left panels), Indonesia (centre panels) and Philippines (right panels). The

$97495^{\text {th }}$ percentile is calculated for 24-hourly accumulations and is displayed as $\mathrm{mm} \mathrm{hr}^{-1}$.

$975 \quad$ Forecast precipitation is shown for lead day 1 (hours 00-24), lead day 3 (hours 48- 

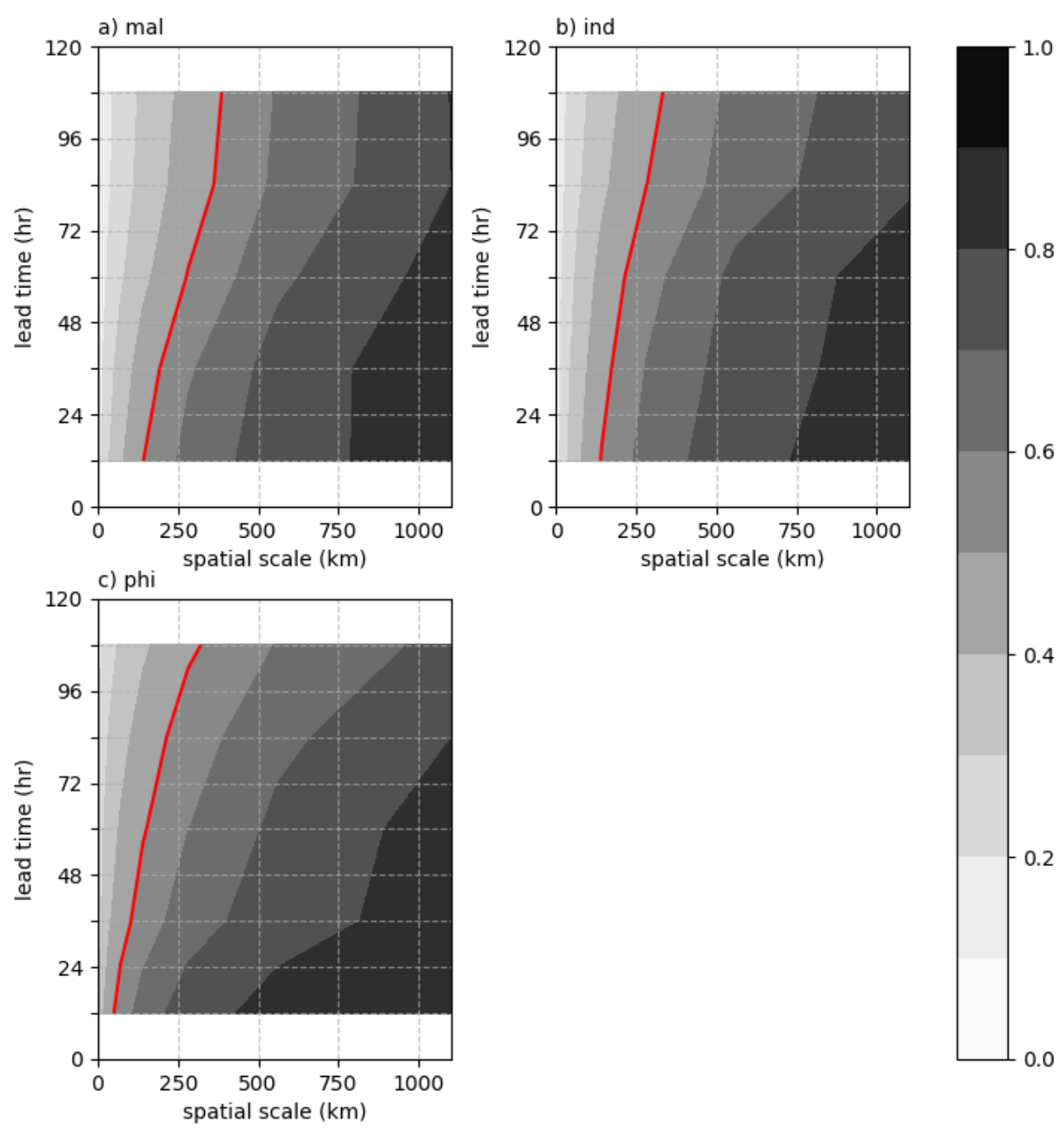

Figure 4: Fractions Skill Score (eFSS) of 24-hourly accumulated precipitation

980 exceeding $95^{\text {th }}$ percentile aggregated over all $4.5 \mathrm{~km}$ forecasts in Oct 2018-Mar 2019

981 as function of spatial scale ( $x$-axis) and lead time (y-axis) for a) Malaysia model

982 domain, b) Indonesia model domain, and c) Philippines model domain. The red line 
a) Malaysia GPM-IMERG

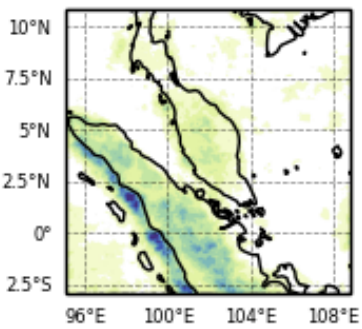

d) Malaysia FC 12-15

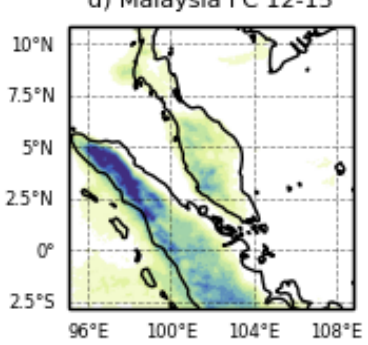

g) Malaysia FC 60-63

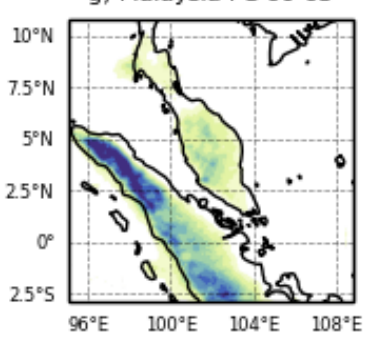

j) Malaysia FC 108-111

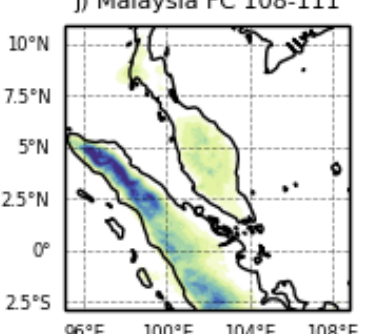

b) Indonesia GPM-IMERG

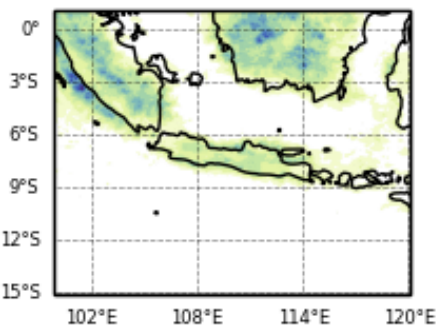

e) Indonesia FC 12-15

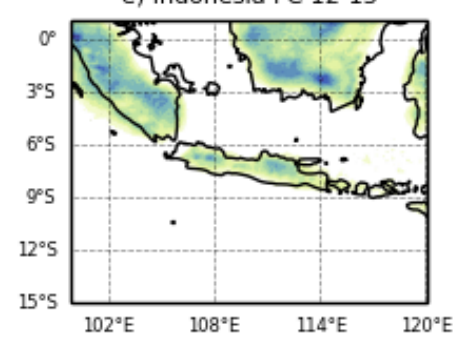

h) Indonesia FC 60-63

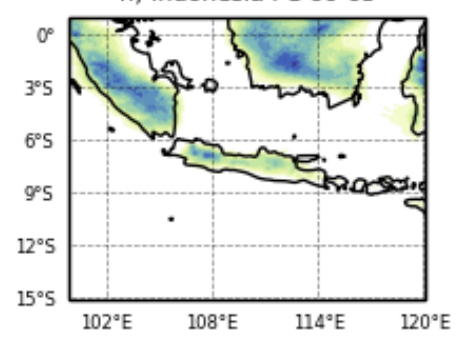

k) Indonesia FC 108-111

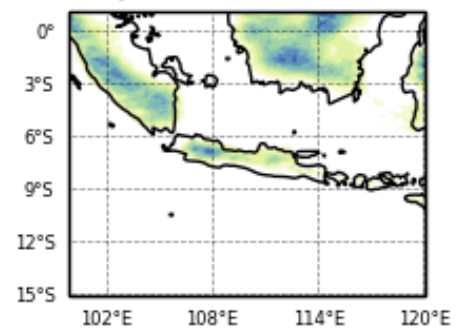

c) Phillippines GPM-IMERG

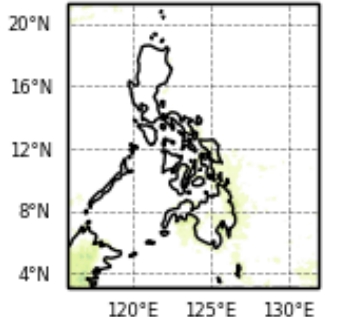

f) Phillippines FC $12-15$

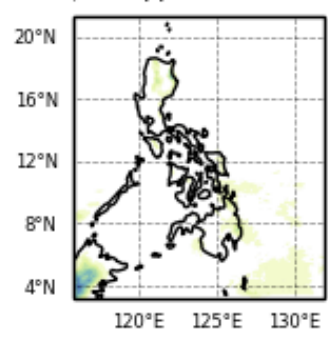

i) Phillippines FC 60-63

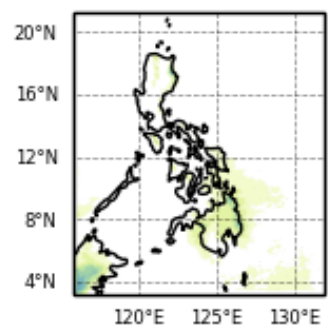

I) Phillippines FC 108-111

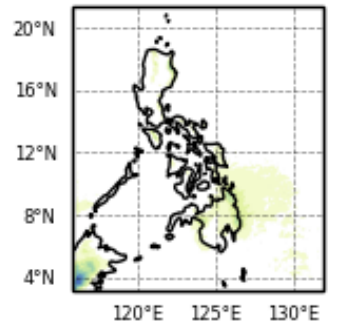

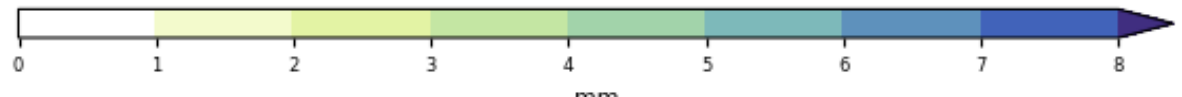

986

Figure 5: GPM-IMERG and $4.5 \mathrm{~km}$ forecast $95^{\text {th }}$ percentile precipitation for

988 Malaysia (left panels), Indonesia (centre panels) and Philippines (right panels). The $95^{\text {th }}$ percentile is calculated for 3-hourly accumulations at 12-15UTC (local evening)

990 and is displayed as $\mathrm{mm} \mathrm{hr}^{-1}$. Forecast precipitation is shown for lead day 1 (hours 1215), lead day 3 (hours 60-63) and lead day 5 (hours 108-111). 

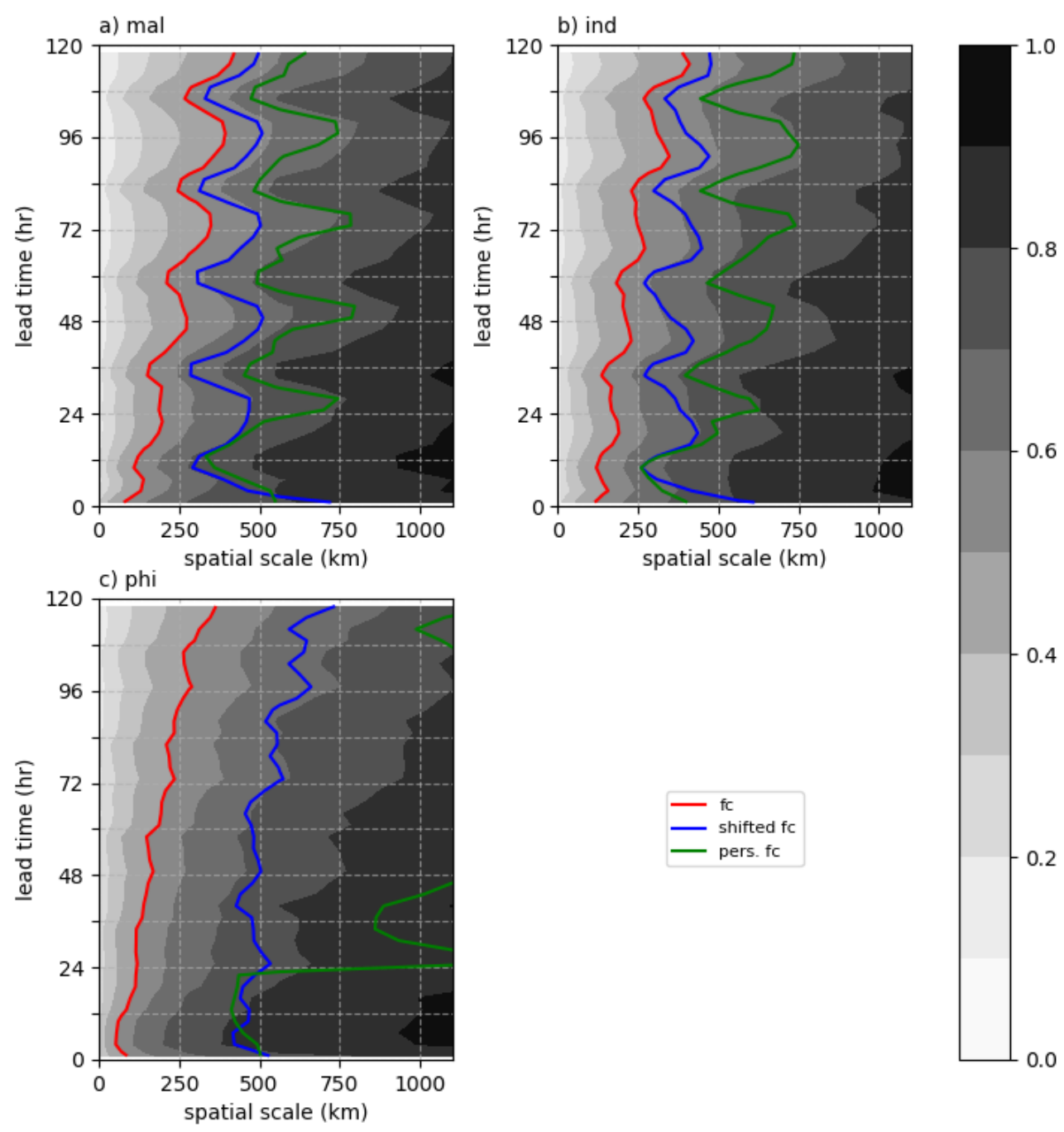

993

$994 \quad$ Figure 6: eFSS of 3-hourly accumulated precipitation exceeding $95^{\text {th }}$ percentile

995 aggregated over all $4.5 \mathrm{~km}$ forecasts in Oct 2018-Mar 2019 as a function of spatial

996 scale (x-axis) and lead time (y-axis) for a) Malaysia model domain, b) Indonesia

997 model domain, and c) Philippines model domain. The red line shows the eFSS=0.5

998 "skilful" contour for 3-hourly forecasts. The blue line shows the eFSS=0.5 contour

999 for 3-hourly "shifted forecasts" where the forecast time-stamp has been shifted a day

1000 ahead of observations. The green line shows the FSS=0.5 contour for a persistence

1001 forecast such that lead time corresponds to the lag of the persistence forecast (see methods). 

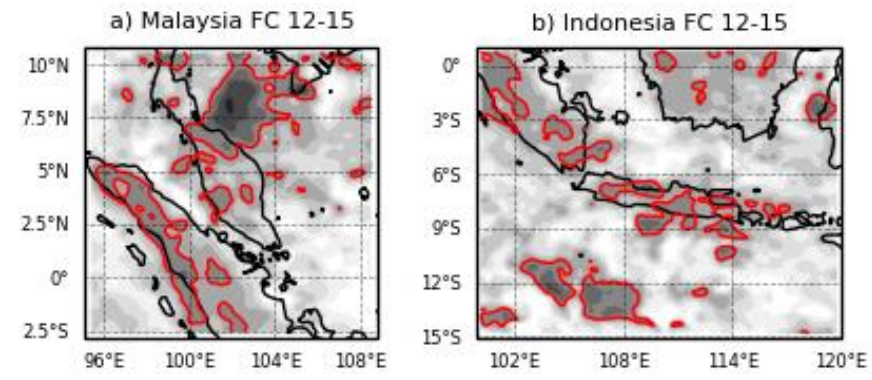

c) Phillippines FC $12-15$
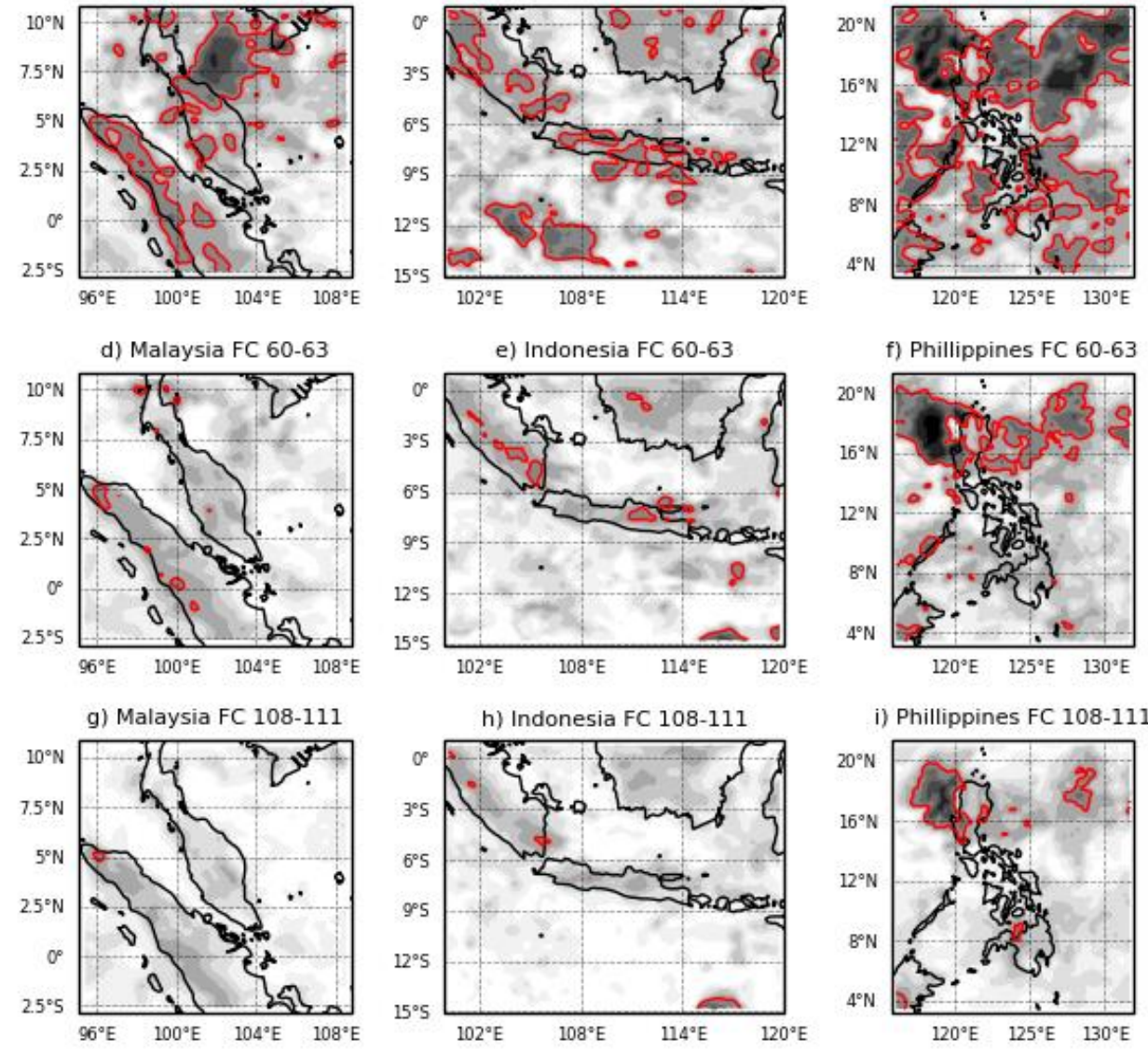

i) Phillippines FC $108-111$
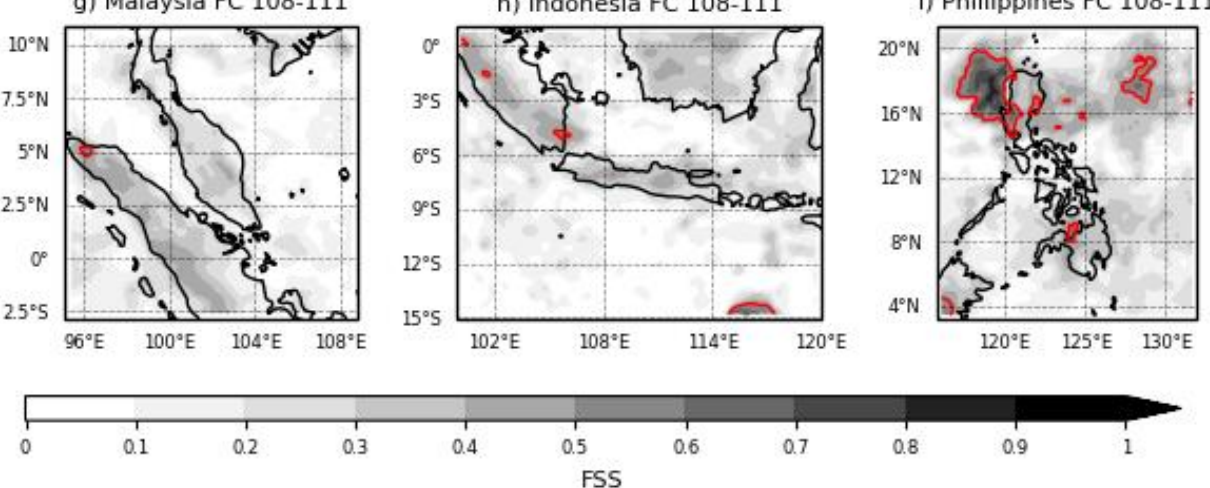

1003

Figure 7: Localised FSS (LFSS) for the $72 \mathrm{~km}$ neighbourhood scale 3-hourly

1005 accumulated precipitation exceeding $95^{\text {th }}$ percentile aggregated over all $4.5 \mathrm{~km}$

1006 forecasts in Oct 2018-Mar 2019for the Malaysia model domain (left panels), the

1007 Indonesia model domain (centre panels), and Philippines model domain (right

1008 panels). LFSS is calculated for lead hours 12-15, 60-63 and 108-111. The red line 

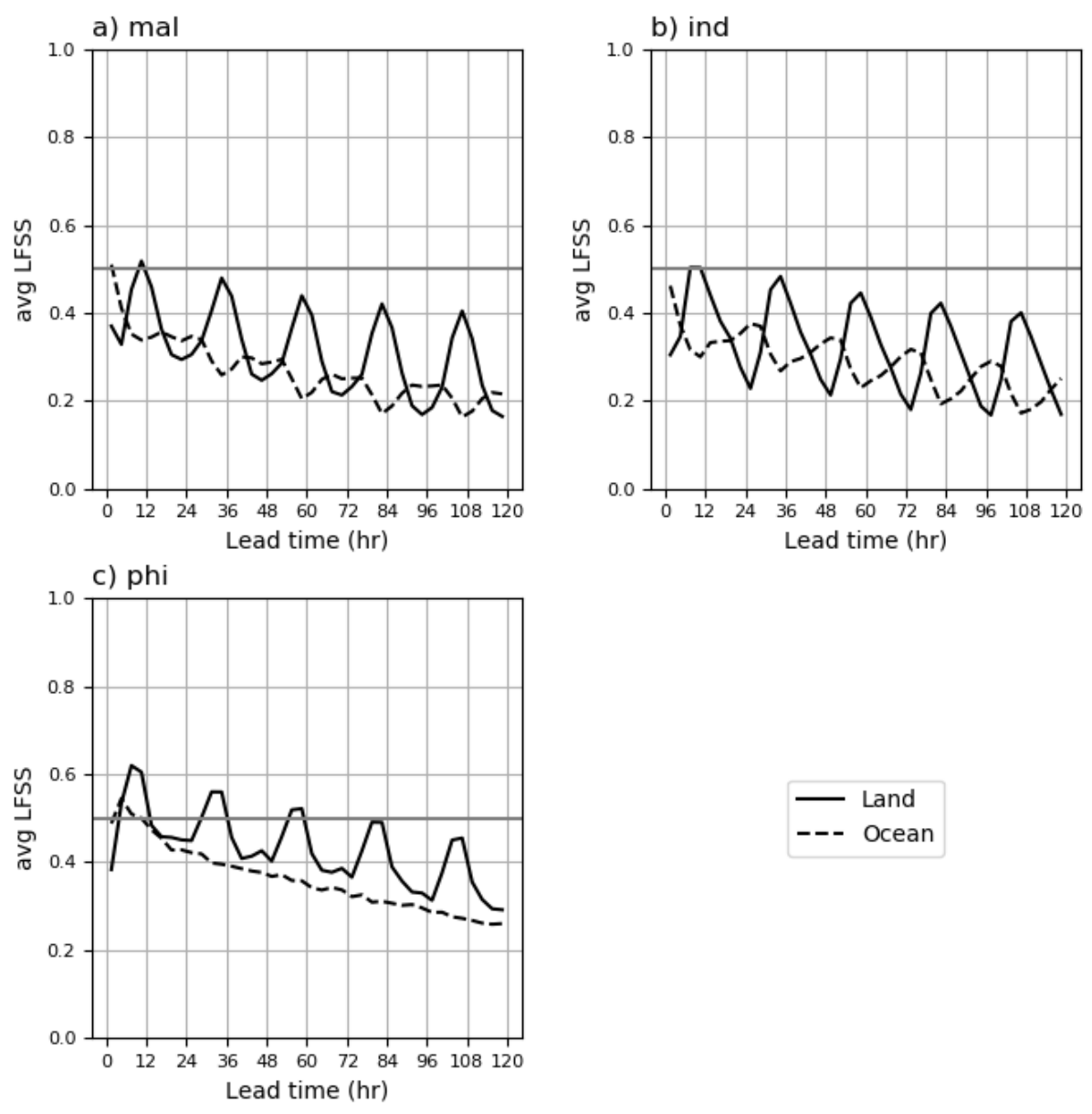

1011

1012 Figure 8: eFSS calculated using land and ocean points for the $72 \mathrm{~km}$ neighbourhood 1013 scale 3-hourly accumulated precipitation exceeding $95^{\text {th }}$ percentile aggregated over 1014 all $4.5 \mathrm{~km}$ forecasts in Oct 2018-Mar 2019 for a) the Malaysia model domain, b) the 1015 Indonesia model domain, and c) Philippines model domain. Solid lines show eFSS $1016 \quad$ over land and dashed lines show eFSS over ocean. 

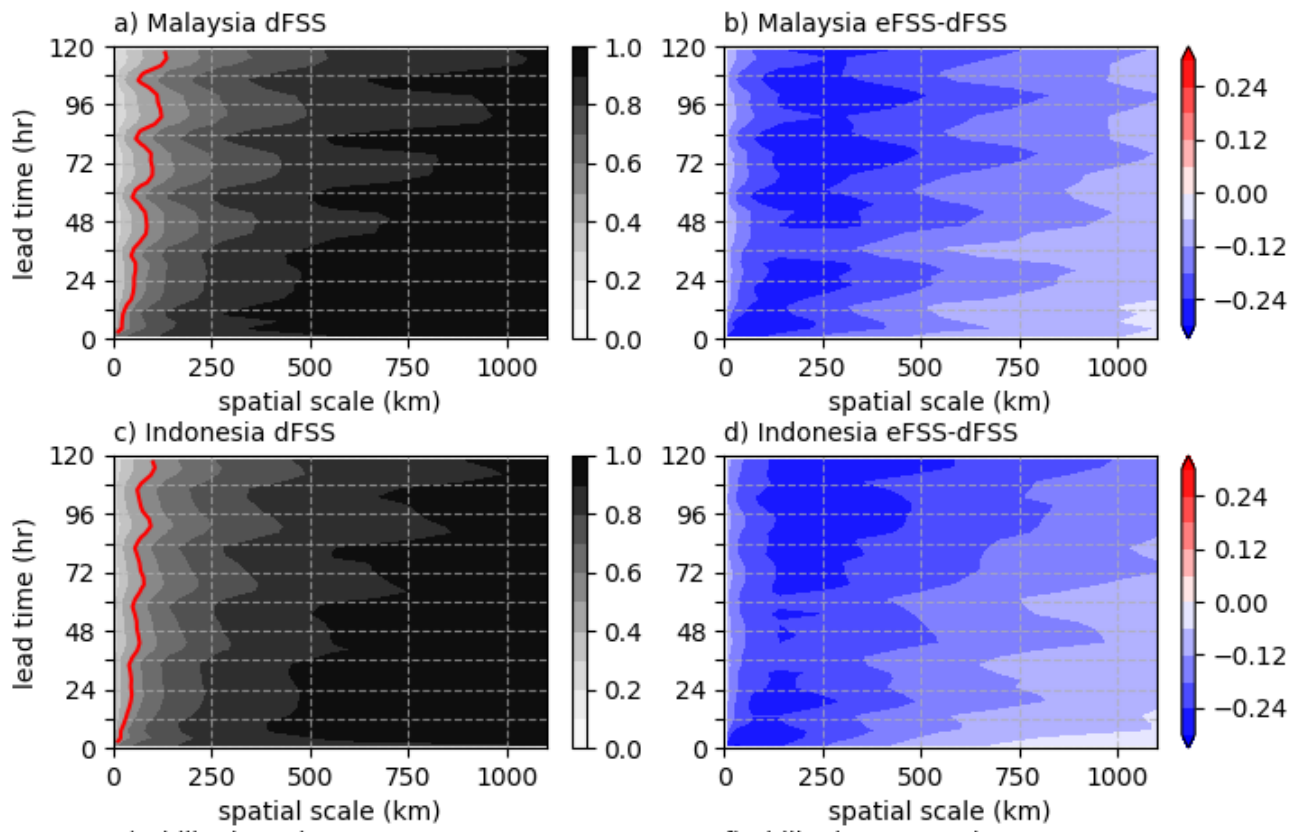

d) Indonesia eFSS-dFSS
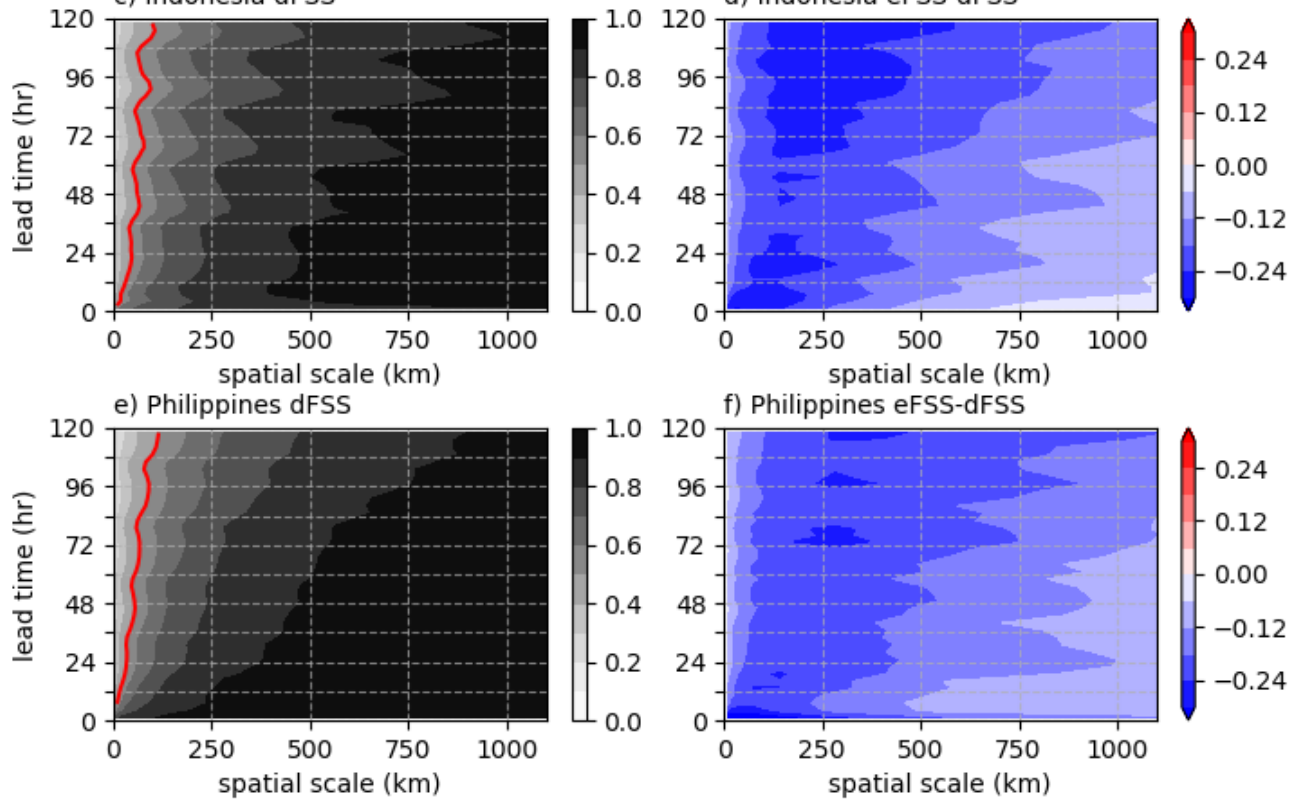

Figure 9: Dispersion Fraction Skill Score (dFSS) of 3-hourly accumulated

1020 precipitation exceeding $95^{\text {th }}$ percentile aggregated over all $4.5 \mathrm{~km}$ forecasts in Oct

1021 2018-Mar 2019 as function of spatial scale (x-axis) and lead time (y-axis) for a)

1022 Malaysia domain (Note - local time is UTC+8), c) Indonesia domain and e)

1023 Philippines domain. The red line shows the dFSS=0.5 contour for 3-hourly forecasts.

1024 The difference between eFSS and dFSS for the same forecasts as in a), c) and e) are

1025 shown in $b$ ), d) and f) such that a negative value indicates the ensemble is under-

1026 spread and a positive value indicates the ensemble is over-spread. 

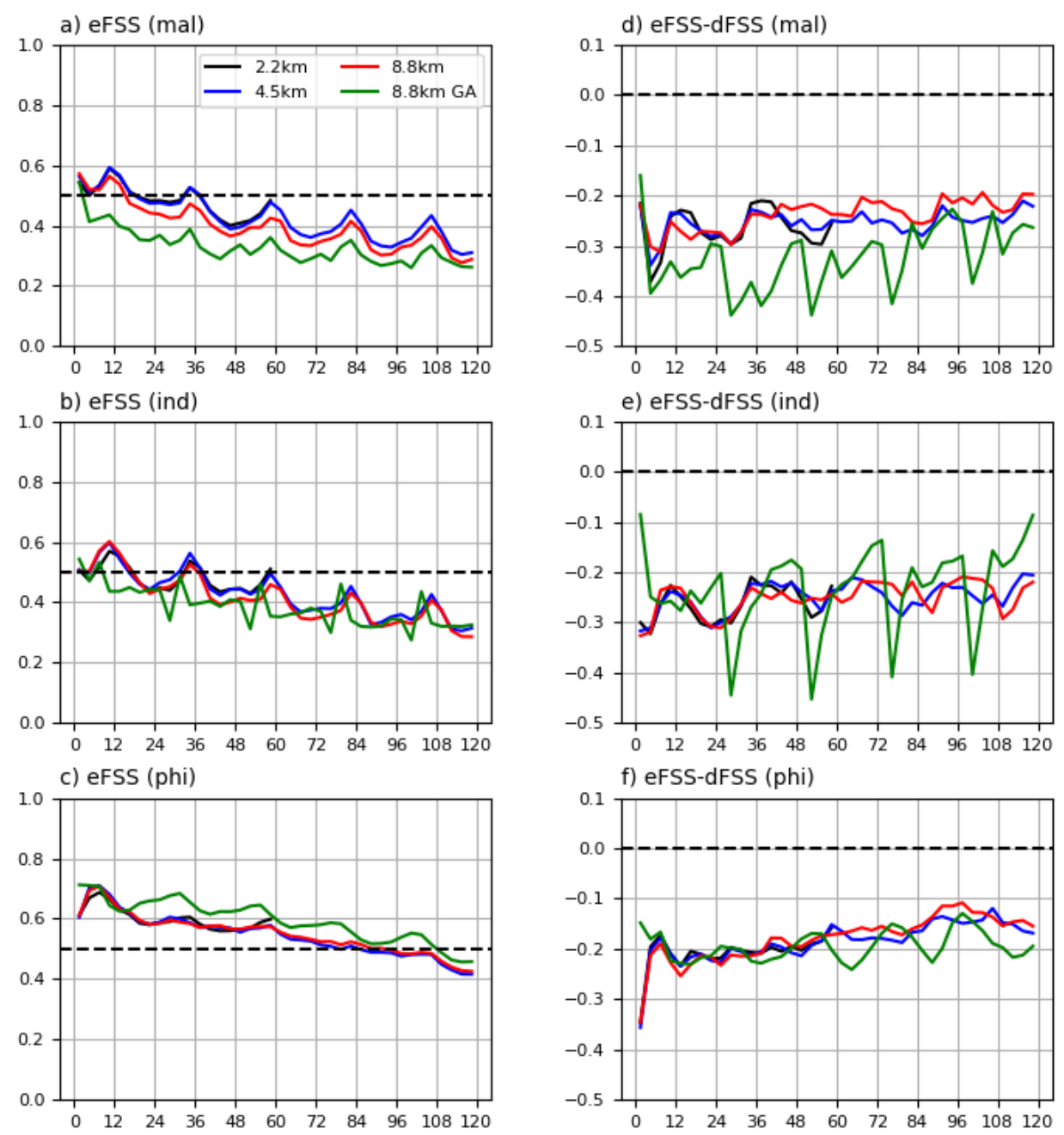

Figure 10: Fraction Skill Score (a-c) and the difference with the dispersion Fraction

1030 skill score (d-f) at a spatial scale of $144 \mathrm{~km}$ of 3-hourly accumulated precipitation

1031 exceeding $95^{\text {th }}$ percentile aggregated over all forecasts in Oct 2018-Mar 2019 as a

1032 function of lead time (x-axis) for a) \& d) Malaysia model domain, $b$ ) \& e) Indonesia

1033 model domain, and c) \& f) Philippines model domain. The color of the lines indicates

1034 the type of forecast; $2.2 \mathrm{~km} \mathrm{CP}$ (black), $4.5 \mathrm{~km} \mathrm{CP}$ (blue), $8.8 \mathrm{~km} \mathrm{CP}$ (red), and 8.8

1035 km GA (green). Horizontal dashed line in a)-c) indicates a skilful forecast

1036 (eFSS>0.5). In d)-f) negative values indicated an under-spread ensemble, positive 
values indicate an over-spread ensemble. Analysis in $d)$-f) is performed over a 1038 subregion of the stated $2.2 \mathrm{~km}$ region (see figure discussion). 